\title{
Engaging Diverse Stakeholders in Interdisciplinary Co-Design Project for Better Service Design
}

\author{
Muneer Nusir, Prince Sattam bin Abdulaziz University, Saudi Arabia* \\ (iD) https://orcid.org/0000-0001-7938-741X \\ Usman Tariq, Prince Sattam bin Abdulaziz University, Saudi Arabia \\ Tariq Ahamed Ahanger, Prince Sattam bin Abdulaziz University, Saudi Arabia
}

\begin{abstract}
The rapid development of information technology (IT) has enabled digital services to evolve continually and support a growing number of internet-enabled devices, along with user diversity. The end-user anticipation within the smart environments, which are internet-enabled delivery networks and innovative technologies. What tools/methods can support the collaborative design and effectively choreograph the design process with dynamic knowledge between service designers and service users? The cooperative design is recognizable in the design environment with a collection wideranged by co-design methods and tools. In-depth interviews uncover contextually appropriate design process requirements from diverse stakeholder groups. A collection of design tools and methods are selected and implemented within a web-based co-design platform. Uncovered design requirements are subsequently applied in extending the double diamond framework prior to operationalization into a design process blueprint with supporting service design tool selection as the main contributions for this paper.
\end{abstract}

\section{KEYWORDS}

Co-Design, Design Blueprints, Digital Service Design, E-Business, E-Government Service, In-Depth Interview

\section{INTRODUCTION}

Information and communication technology (ICT) is an active domain for conveyance and rapid evolution within the IT field at a rate that affects various aspects of our lives (Kaschek et al., 2006). It also contributes to the advent and advancement of the most recent digital services (Stegaru et al., 2015). Typically, e-Government has been conceptualized as the use of ICT by governments along with administrative organizations in changing or improving structures, procedures that are followed, and operations of the government (OECD, 2003). Furthermore, the goal of e-Government is the creation and offering of satisfactory e-services to its people, organizations, along with other civic and private sectors. However, Heeks (2003) stated that a high failure rate of e-Government in unindustrialized nations has been investigated with estimates that $35 \%$ of governmental projects failed completely, $50 \%$ failed partially, and only a mere $15 \%$ of the proposed projects had been successful. Because of 
the failing projects, there have been oppositions towards future projects because trust and credibility is not present on the part of service providers and users of the e-Government services (Twizeyimana \& Andersson, 2019).

In fact, for developing nations, e-Government services are generally offered by service providers internally, while frequently overlooking the users of the services (Axelsson \& Melin, 2007; Bridge, 2012). Consequently, service delivery is often jeopardized without any consideration of the users of the services in terms of what they desire and expect within the service framework processes (Lenk \& Traunmüller, 2002; Wu, et al., 2013; Zhao et al., 2008). Moreover, the marginal effectiveness of e-Government services creates a situation where the providers are not obligated to meet the real needs of citizens (service's user). Hence, there is a need to maximize the endeavours towards bridging the requirement gaps between them. Therefore, the authors adopted a 'co-design approach' to assist the government as a provider of services to work towards collaborating with users of services; such that the provider and user become partners in a collaborative relationship that is beneficial to the entire citizenry (Chang et al., 2005). This approach seeks to maximize the opportunities of users in participating and collaborating with providers of services through providing them appropriate design tools or methods, which facilitate their involvement (i.e. participation and collaboration) in each stage of development of e-Government services and to identify services requirements in accordance with the needs of users (Sanders and Stappers, 2008). Further detail is reported in the consequent sections.

It is important to engage fully diverse stakeholders in the process of designing services, especially the users of services who are supposed to benefit and use the outcomes of the services (Sanders and Stappers, 2008). Additionally, those responsible for management of users also expect and need various aspects that require effective techniques to enhance collaboration (Stappers et al., 2011). Co-design is progressively becoming more prominent in numerous organizations and businesses (Binder et al., 2008). Sanders and Stappers (2008) used the word "co-design" to make reference to "collective creativity' (i.e. something common between multiple individuals), which is applicable to the whole scope of a design process (Steen et al., 2011). The latter also refers to creative collaboration in the process of development and using services. For example, in co-design, diverse stakeholders, including service providers, designers, researchers and users of services, who have expertise in accordance to their experiences; work together (Visser et al., 2005). Limited collaboration among users in the entire course of designing e-Government services is usually observed (Anthopoulos et al., 2007; Følstad et al., 2004; Olphert \& Damodaran, 2007). Hence, it is critical to focus more on to pay more on involving users of services in the whole design process (Sanders and Stappers, 2008). We employ the phrase 'design process' to imply the process of communication and interaction between users of services and providers of service based on their experiences and perspectives (Mager, 2008; Glushko \& Tabas, 2009).

The main of this paper is to attain a deeper understanding of these unmet requirements for Government to Citizen (G2C) e-service design and ways of attaining a better match of design needs through an appropriate process of design. A consequence of the mismatch between service design requirements (end-user needs) and the service design activities is an increasing risk resulting in fewer benefits from the design process than would otherwise be realized (Sanders and Stappers, 2008; Steen et al., 2011). In this paper a conceptual "design-led" contribution from a design of a digital service is presented.

\section{The Objectives of the Theoretical Contribution}

1. Distinctive methods, which can enhance the standard value of $\mathrm{G} 2 \mathrm{C}$ services while maximizing opportunities for users in regard to participating in the process of design,

2. Reduce the gaps in terms of requirements between desires of users of services (citizenry) and the designers of the $\mathrm{G} 2 \mathrm{C}$ e-services, and 
3. Enhance the standard and potency of G2C e-services by embracing a co-design strategy along with instruments and approaches that will facilitate participation of users in the entire process of design.

\section{Research Questions}

1) How G2C services could be delivered?

2) How would you like us (service provider) to do service design to you (service user)?

3) What type of services should be delivered and by what means?

4) How do you experience services - face obstacles and daily frustration?

5) What are you (service users) willing to contribute and/or improve their services experience and outcomes of the services?

Moreover, throughout this paper, we will explore the advantages of co-design approaches in design environments intended to facilitate varied engagements by stakeholders with a commitment to particular articulation and practical benefits associated with e-service design. In the next section (section 2), we intend to review some theoretical background literature on the context of e-Government service. Subsequently, the methodology (section 3) will detail research methods while focusing on the research steps (understanding, imagining, and building). Fourth section, will present a case study for fieldwork testing that will include an evaluation and discussion. Ultimately, the paper will present and explain limitations and future direction, after which a conclusion will be provided at the end.

\section{Background}

\section{Background of E-Government Services}

The citizenry is supposed to access e-Government services easily and reliably in order to support various kinds of e-Government interactions including government to government (G2G), government to business (G2B) and government to subject (G2C) (Gupta, et al., 2008). Services provided by e-Government continue to experience issues and problems, particularly in regards to execution, as a result of neutral un-met desires in commission approaches. Furthermore, these aspects are considered as among the numerous aspects resulting in e-Government failure, especially in emerging nations (Choudrie, et al., 2009). Appreciations of the progress of e-Government and exploration of aspects that determine development of e-Government have been gaining momentum in communities analysing e-Government (Scholl, 2014).

The word "e-Government" originated in the late 1990s, but its computer past dates back to the dawn of the computing era of governmental organizations. However, the research on 'Information Technology in Government' dates back at least to the 1970s (Rodger et al., 2020). Latest surveys have demonstrated the effective implementation of government programs to help suit citizens' needs. These facilities are now becoming more accessible, effective and affordable. Although some of the oldest computer problems with e-government persist, like office automation, the e-government service architecture does not matter the same. Others, including service processing, decision making and values have been believed to be more appropriate for this research. Present emphasis is on improving the happiness of residents and improving the quality of life. In recent years, government-based concrete e-services were not citizens-centred and did not fulfil end-user needs. While e-Government platforms have become traditional contact networks between the public and government, the citizen-centred approach to e-Government programs is significant. The organization, which places people at the centre of their operation, should rely specifically on human rights. At least the data integration of different governmental agencies is an interconnected structure of electronic services. 
This paper focuses on Government-to-Citizen (G2C) services and how the government provides numerous services to its citizenry, including tax collection, welfare payments, renewal of driver's licenses, facilitating government agencies, defining passport issues, and various social and health care services (Fogli \& Provenza, 2012). Generally, the provision of G2C e-services is the responsibility of service suppliers, which has created a situation where the desires of the users of the services in emerging nations are overlooked (Lenk, 2002; Parent et al., 2005; Heeks, 2003). This has created various socio-technical challenges and a lack of programming skills. E-Government is supposed to reduce the gap in requirements between citizenry and governments, and to facilitate getting of high potency and superior online services; in order to encourage the citizenry to utilise the services (Parent et al., 2005). Among the vital queries associated with G2C e-service is: 'Which vital requirements/ aspects enhance an understanding of the development of the design process of e-services?' Service delivery is usually affected without any consideration for the user of the service. Exclusive staff working for service providers as e-services design consultants possesses appropriate knowledge that they can apply in addressing the needs of G2C e-services. To develop such services, many interactions and communication are required between designer and developers of the service and users of the service. The gap between users of the service (i.e. citizenry) unmet desires and needs of $\mathrm{G} 2 \mathrm{C}$ e-service $\mathrm{G} 2 \mathrm{C}$ and inadequate engagement of users of the services in the entire process of designing e-Government services can lead to failure in regards to developing e-Government services (Fogli \& Provenza, 2012; Palvia \& Sharma, 2007; Choudrie et al., 2009).

E-Government Systems should be available and trustworthy, promoting multiple modes of e-Government engagement, such as government to citizens (G2C), Government to Businesses (G2B), Government to Government (G2G) and Government to Employers (G2E). E-Government programs do face difficulties and problems, in particular during the deployment process owing to this discrepancy between unaddressed stakeholders' needs and program designs (Scholl, 2014). The gap is regarded as one of the important factors which lead in the developing nations to a breakdown of the e-Government agenda. The e-Government research group developed an interest in comprehending the growth of the e-Government and addressing factors that affect e-Government growth.

A citizen-centred approach offers the ability to develop a clear understanding of the residents' preferences and desires and how they contribute to e-governmental facilities. Moreover, e-Government programs should not only be customized to the interests of intended residents but must also be compatible with the requirement and working processes of suppliers of services (Rodger et al., 2020). If a disturbance happens, the effects are decreased in the efficiency of the service rendered. Besides, it has been pointed out that governmental ICT programs are likely to break down because of a lack of emphasis on service providers' needs, aspirations and joint activities of those individuals using these facilities.

The paper provides a new, user-focused perception of service design that discusses e-Government institutions' perceived efficiency with personalized participation by stakeholders. Also, this paper aims to examine sound strategies which enhance the quality and usefulness of e-Government facilities in the process of design. The research will also fill the difference in preferences between the unanswered demands of citizens and service suppliers and planners (Rodger et al., 2020). In interviews, a repertory grid (RepGrid) methodology was used to more consistently define, from the research participants' perspective, the criteria and the features of the G2C e-service development process. Several studies also reveal that a diverse list of concepts is sufficient in the smaller sample size. In reality, this analysis is about who utilizes the G2C (service users) service as these target users can express their desires and inspiration.

The interview has been selected as a way to discuss the problem more thoroughly. A total of 23 repertory grid interrogation lasting 45 to 90 minutes were performed. The analysts, however, omitted four interviews based on the context of the interviewer and their experience with the field (the phase of service G2C advancement) (Rodger et al., 2020). Each interview began with a summary of the concerns of the researchers, and then they proceeded to incorporate the RepGrid methodology to 
simplify the implementation of the interviews to ensure participants comprehend the tasking. Nineteen test subjects attended this thesis. This report interviewed people with government officials via two key government services agencies (service providers). The first is that of the MOICT (Ministry for Information and Communication Technology) and the second is the NITC (National Information Technology Centre). Each company performed three semi-structured surveys with government staff accountable for the design and implementation of G2C services.

A second category represents the employees of the administration, who serve in public institutions and function as a bridge between the people and government. These workers should not surprise, since they face challenges when coping with end-use and facilitating citizen relationships, with a greater understanding of G2C system development concerns and unfulfilled citizens' needs. The very last group is composed of typical residents (end users) of a wide variety of genders, races, jobs, and different professions (university students, staff members, employees and managers). There are seven, six or six interviewees, per group (Rodger et al., 2020). All interviews have been transcribed and documented. Accompanied by the repertory grid surveys, these preliminary interviews were listed below. This document reports the results of the repertory grid analysis to explain the criteria (and constructs) applied for an integrated G2C e-service development process.

In the Word Sense Disambiguation (WSD) discourse, several methods addressed and fields discussed. Three distinct fields of natural language processing (NLP) have also been studied from a cognitive scientific point of view, namely the simulation of the use of human language in spoken dialogue, referential practice, the production of comparisons and WSD. Extractive summaries, classification of the emotions and corpus-based stemming methods derived from this area have been used in topic studies as diverse as medicine and finance. Examining internal lexicons with psychological research shows that specific senses are easier to stimulate than abstract senses and that complex comparisons are more quickly activated than small paradigms. A new synthesis of ontological engineering concepts and the moral discourse behavior with spatial data was tested in recent developments on the semantics of natural language articulation. A probabilistic overall performance model has been proposed to measure the probability the user response may be utilized for maximizing the timeout.

Several scientists have identified how to construct a deeper semantic representation of Arabic texts by signing and applying a computer model for an Arabic semantic parser. They also demonstrated that FrameNet and WordNet integration would increase the precision of the ambiguation. Automatic extraction of synonyms employed it to create the Quranic Arabic WordNet using conventional Arabic dictionaries has also been established. The program increased the reminder of semantic Qur'an quest by $27 \%$. Numerous analysts have defined the tagger for speech (POS), used for the grouping of unannotated natural language words with POS marks into categories like a noun, adjective and verb. Qaiser and Khan (2010) suggested a hypothesis of a POS tagging in the Arabic language for the collection results and provided various situations in which a morphosyntactic word's status depends on the state of the corresponding words. Enhancing the IR model will upgrade the basic model for word bags and significantly increase the semantic indexing methodology based in Arabic WordNet. By executing on a large Arabic corpus, genetic algorithms can be more accurate prediction than memetic algorithms and Bayes naïve classifiers. Optimization of the ant and bee colony appears to be better than that of the genetic and virtual algorithms. A lemmatization in Arabic was developed, containing two modules. They embraced hidden Markov design and authenticated this strategy using an identified corpus comprised of around 500,000 words.

\section{E-Government Services in Pakistan}

In Pakistan, e-Government was launched in late 2002; it was initiated and started as a department within the Science and Technology Ministry, whose main endeavour is to monitor various e-Government associated projects, so as to offer practical guidelines for the developing services (Warriach and Tahira, 2015). E-Government's main objective is provision of support to organizations within the public 
sector as a way of increasing productivity, efficacy, and openness through ICT to enhance service to citizenry, as end-users (Ovais Ahmad et al., 2013). In Pakistan, the ICT sector is responsible of developing of e-Government services, through creation of a vibrant and feasible strategy to focus on all factors of day to day lives of all citizenry. Moreover, the government in Pakistan has been able to complete various activities aimed at reforming social and economic aspects, through development of a robust ICT sector to emphasize on improved e-Government services offered to all citizenry (UN, 2012; Ali et al., 2018).

Similar to other emerging nations, Pakistan has e-service problems, including a very modest ICT infrastructure, low rates of literacy, demographic factors (i.e. age and gender), awkward and slow development of e-Government services (including lack of knowledge, ease of use, influence by the society, challenges associated with technology, privacy of data and issues linked to trust, affect satisfaction of services provided by e-government between providers of the service and the users in Pakistan) and cultural issues (Ovais Ahmad et al., 2013; Rehman et al., 2012; Chandio et al., 2018). According to Almakki (2009) e-Government services have been associated with difficulties in emerging nations, which have similar problems at the developmental stage of these services. Qaiser and Khan (2010) also state that a number of restrictions exist (i.e. Inadequate ICT facilities, and insufficient implementation of IT) contributing to obstruction of the expansion progress of e-Government services ((Ali et al., 2018).

A study carried out by Rehman et al. (2012) explored the aspects influencing the implementation of Pakistani e-Government services. They focused on the main aspects (i.e. demographic factors, trust toward e-government, website/service design, and quality of service) of implementation of e-Government services by users through recommendation of an integrated theoretical model (Butt et al., 2019).

\section{Design Methodologies and Approaches}

User-centred design (UCD) is an iterative design process used in formulating innovative solutions (van Velsen \& van der Geest, 2012). The key phrase, 'user-cantered design' was created by Donald Norman in 1980). He proposed four simple recommendations on how a scheme should be: (a) accomplish it without challenges to govern what arrangements are conceivable at any instant; (b) form noticeable conditions, containing the intangible prototypical of the scheme, the substitute activities, and the outcomes of engagements; (c) constitute it in a straightforward manner to assess the contemporary status of the method; (d) monitor expected mappings between intents and the mandatory engagements and between the data that is evident, and achieve the understanding of the method state. The critical coordination of UCD is based on understanding, confidence, repetition, and imaginative assurance, certainty in creation, implementation obscurity, and understanding failure risks for contingency planning.

UCD progression concludes in six stages:

(1) Postulate the procedure framework and operators' requirements;

(2) Stipulate occupational necessities;

(3) Construct strategy from irregular conception to completed project;

(4) Assess strategies with use case adoption verification;

(5) Put invention into practice;

(6) Set out the ultimate invention and figure out if user requirements transform.

User-centred design (UCD) methodologies were established in 1970 and ultimately became accepted widely and adopted in 1990 (Sanders \& Stappers, 2008). Handler outlooks and concepts are merged into the software improvement progression regularly to ensure a better system or service deployment (Wever, et al., 2008). UCD emerged as being greatly suitable in designing and developing products for end-user (van Velsen \& van der Geest, 2012). Figure 1 explains a caricature displaying 
the deficiency within the classical user-centred process of design compared to the co-design approach, and the rationale for transforming to co-design approach. Sanders and Stappers (2008, p.11) stated "the user is a passive object of study, and the researcher brings knowledge from theories and develops more knowledge through observation and interviews". Moreover, "The designer then passively receives this knowledge in the form of a report, and adds an understanding of technology and the creative thinking needed to generate ideas, concepts, etc." (Sanders and Stappers, 2008, p.12). Nevertheless, an analysis is critical to mentor participants at the 'performing' level of creativity, supporting at the 'adaptive' level, supporting platforms for resourceful manifestation at the 'innovative' level, and suggest a delicate account at the 'designing' level (Sanders \& Stappers, 2008).

Figure 1. The classical state of the user-centred design next to Co-design (Cited from Sanders and Stappers (2008))

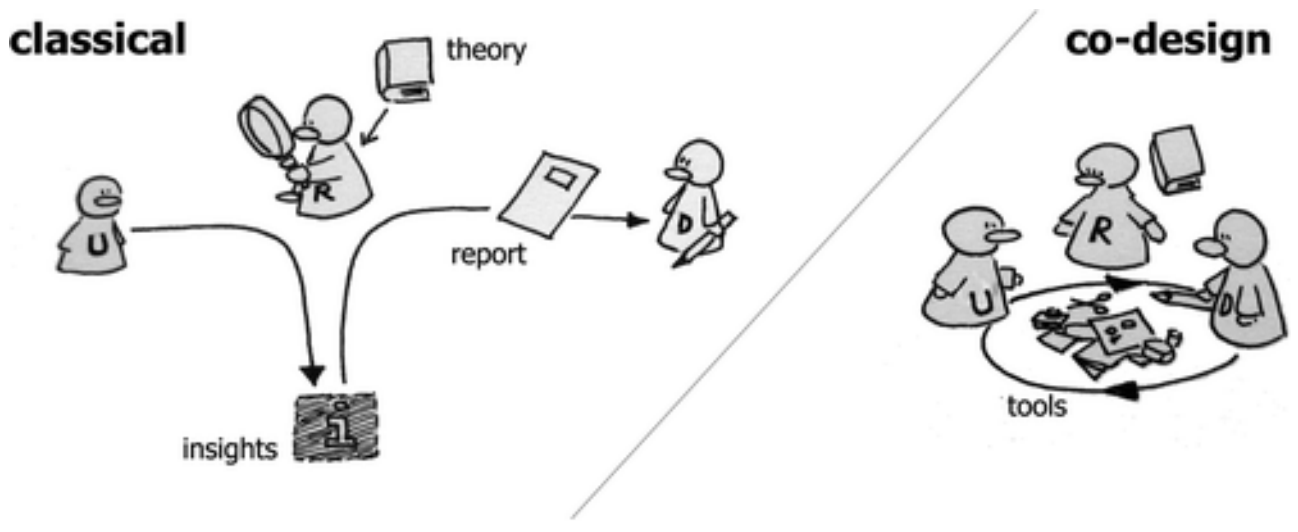

Current scientific advancements have compelled growth of participants from submissive data consumers in to statistics producers (Fogli \& Provenza, 2012; Friedrich, 2013). Figure 2 grants a scale on users (inhabitants) and creators (developer). Each method represents a prototype evolution for the participant from a submissive user into a data producer (Graening \& Sendhoff, 2014). Participants are ready and would also wish to outline their amenities by altering them to their own distinctive requirements (Ardito, et al., 2012). For that reason, methodologies are essential to react to this desire/ need and discover the practice of a meta-design method for services provided by e-Government. As shown in (Figure 2) a meta-design can be defined as an evolving theoretical scheme within the shared design process, focusing on the practice of policy as well as targets to outline and generate socialtechnical settings that allow users to become innovative (Fischer \& Giaccardi, 2006). Nevertheless, e-services should not only fulfil prerequisites of the participants they are meant to serve, instead, they must also adhere to requirements and satisfy operational needs of benefactors of the service as service suppliers and conveyors.

\section{Typical Phases of Design Process: Double Diamond Model}

The Double Diamond model (DDM) can be defined as an basic graphic plan of the process of design as a creative process (See Figure 3) distributed into four separate stages (Discover, Define, Develop, and Deliver) representing a typical design process phase (British Design Council, 2005). These creative processes reflect various potential ideologies before refining (i.e. divergent ideas) and narrowing down ideas to the most suitable ones (i.e. Convergent ideas). DDM designates these four stages to work together as a map design providing guidelines for the organization of thoughts in order to improve the creative process (JustInMind, 2018). 


\section{Citizens}

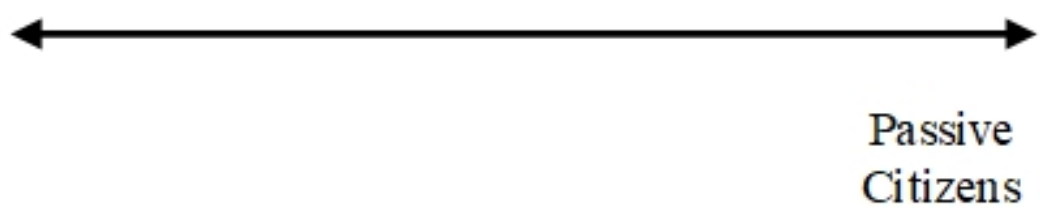

\section{Active Citizens}

\section{End-User}

\section{Power User}

\section{Domain User}

\section{Meta-Designer}

Figure 3. Double Diamond model (Adapted from the British Design Council, 2005)

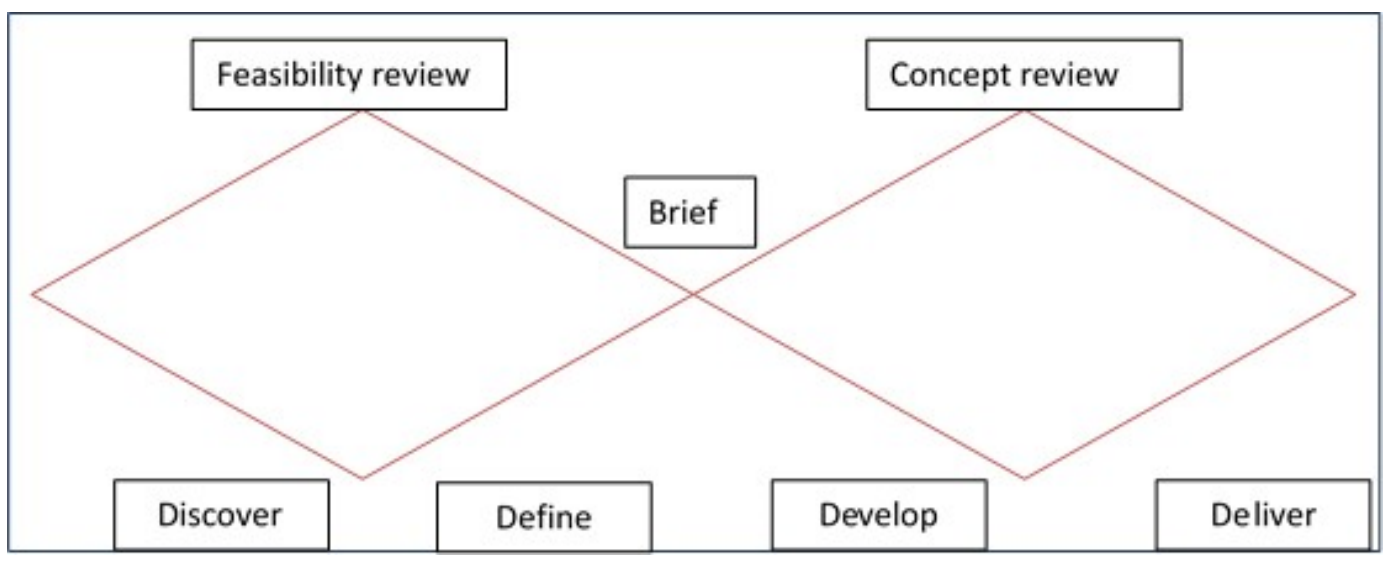

The creative process is an iterative process (not a linear process), which implies that the specific ideas are developed, tested, refined several times to match diverse thoughts and perspectives of stakeholders; weak ideas are omitted in the design process (British Design Council, 2005). We reviewed literature that directly explored 'DDM', which demonstrated that research studies (Pierri, 2012; Hinman, 2012; Peter Merholz, 2013) have adopted DDM in their research by adapting it to fit the domain context. "Modes of thinking either expand to a divergent approach, or a more focused convergent approach, in order to refine the ideas explored at the previous divergent stage" (Clune \& Lockrey, 2014 p. 4). For example, 'DDM' as a design process model is used in different companies: 
Scott and Fyfe (2014) present an example of such a company, which has embraced 'DDM' to develop a huge of textiles for several market areas worldwide. Better Services by Design as a study plan used 'DDM' to enhance services associated with social and health care (User-Centred Healthcare Design, 2012). In addition, Copenhagen Business School (CBS) along with Technical University of Denmark (TUD), which have had several activities and research projects in 2014, utilised the 'DDM' as a creative process through conducting innovation and entrepreneurship in education.

Table 1. A sum up outline of Double Diamond Design process that includes its stages, descriptions, objectives, along with common design instruments and approaches that are adopted in each stage

\begin{tabular}{|c|c|c|c|}
\hline Phase & A Brief Description & Objective & Popular Design Tool/method \\
\hline Discover & $\begin{array}{l}\text { This instigates with assembly data } \\
\text { about a problem (understandings, } \\
\text { designs and/ or motivations). } \\
\text { Regularly; at this level, inventors } \\
\text { can reduction down their problem, } \\
\text { present their supposition, and } \\
\text { defining perfect ways to acquire } \\
\text { knowledge. }\end{array}$ & $\begin{array}{l}\text { To recognize and } \\
\text { contextualize the real } \\
\text { problem or prospect. }\end{array}$ & $\begin{array}{l}\text {-Journey Mapping } \\
\text { - User Diaries } \\
\text { - Service Safari } \\
\text { - User Shadowing }\end{array}$ \\
\hline Define & $\begin{array}{l}\text { Signifies a purifying of the notions } \\
\text { and perceptions are acquired from } \\
\text { discovering. Moreover, learning } \\
\text { and investigation the framework } \\
\text { concerning product improvement, } \\
\text { and evaluate the likelihood study for } \\
\text { the project } \\
\text { what can be done and what cannot. }\end{array}$ & $\begin{array}{l}\text { For cleaning all collected } \\
\text { data that was acquired from } \\
\text { stage one, and clarifying } \\
\text { every module in the } \\
\text { anticipated project }\end{array}$ & $\begin{array}{l}\text { - User Personas } \\
\text { - Brainstorming } \\
\text { - Design Brief }\end{array}$ \\
\hline Develop & $\begin{array}{l}\text { The improvement phase is based on } \\
\text { fetching a lot of multi-disciplinary to } \\
\text { work together - various participants } \\
\text { together including core inventors, } \\
\text { engineers, service's users and } \\
\text { designers who have the capability } \\
\text { required in the project. }\end{array}$ & $\begin{array}{l}\text { To advance and perfect the } \\
\text { practitioners engineers' } \\
\text { ideas. }\end{array}$ & $\begin{array}{l}\text { - Service Blueprinting } \\
\text { - Experience Prototyping } \\
\text { - Business Model Canvas }\end{array}$ \\
\hline Deliver & $\begin{array}{l}\text { Signifies the preceding stage, } \\
\text { where the subsequent invention or } \\
\text { provision is completed and launched } \\
\text { in the applicable market. }\end{array}$ & $\begin{array}{l}\text { To determine that the end- } \\
\text { user' response has been } \\
\text { evaluated which imitates a } \\
\text { justifiable perfection. }\end{array}$ & - Scenarios \\
\hline
\end{tabular}

\section{End-User Participation in the Service Design Process}

Knowledge on involving end-users in the process of designing is critical, since they represent consumers of services who should benefit and utilise the end service or product (Sanders, 2008). Various research studies have found that in order to develop successful new services, service providers require a full understanding of user needs, which requires the involvement of users of the service (i.e. participation) in the process of development (Alam, 2002; Stappers et al., 2009; Karlsson et al., 2012). One believable assumption is that involving the users in the process of innovating the service is more essential compared to innovation process of tangible products. Involving service users in the design process will create innovative ideas through originality and higher perceived value on the part of the users of the service (Glushko \& Tabas, 2009). However, attainment of these points of view and ideas is somewhat challenging. Additionally, the outcomes are also determined by the manner in which the involvement of the users will occur (Magnusson et al., 2003; Holgersson, \& Karlsson, 2014). 
In fact, there are no straightforward guidelines in previous research on how to achieve user involvement to generate ideas/perspectives for new e-services (Karlsson et al., 2012). To make it somehow applicable, design research should match the four recommended criteria identified and suggested by Magnusson et al., 2003. First, there should be an agreement to involve users in development of the new service (i.e. purpose of involvement). Secondly, users should be allowed to participate from the early phases of the process of development (i.e. phases of involvement), which is a help to generate and elicit new ideas and concepts based on users' experiences. Alam (2002) has identified ten phases where users are involved: (1) strategic planning, (2) generation of ideas, (3) screening of ideas, (4) business analysis, (5) creation of the well-designed team, (6) process and service design, (7) training of personnel, (8) pilot running and testing the service, (9) test marketing, and (10) commercialization. Third, the involvement should consider the users of the service as endusers, not parties in business-to-business relationships (i.e. intensity of involvement). Finally, the empirical studies must compare findings between the users who are involved and those who are not involved (i.e. modes of involvement)

\section{Research Methodology}

A qualitative method was preferred for conducting this research given the exploratory nature of the enquiry. In-depth interviews were conducted in order to allow inclusion of set of questions while making it possible to explore issues further based on the responses of the interviewees (Kumar, 2019). Denzin and Lincoln (2000, P.3) contend that a qualitative study is comprised of an interpretive methodology: "This means that qualitative researchers study things in their natural settings, attempting to make sense of, or to interpret, phenomena in terms of the meanings people bring to them". The in-depth interviews method was conducted with diverse stakeholders involved in the design process to capture requirements and test it in $\mathrm{G} 2 \mathrm{C}$ e-service. $\mathrm{G} 2 \mathrm{C}$-service context is used to identify the current service context and the stakeholder groups impacted by the G2C e-service chosen.

Figure 4 provides an overview of the research steps that were followed (JiSC, 2017) starting with getting the perspective of stakeholders through in-depth interviews (Dworkin, 2012) as a way of collecting stakeholders' insights and perceptions that would allow development of a design blueprint. In-depth interviews are conducted with three stakeholder groupings comprising of 48 participants in total (service providers, users of services, and frontline-staff in provision of the service). Different backgrounds, particularly on the part of users of the service, assisted in identifying individual requirements of the design process. Interviewees were encouraged to verbalize their reasoning process. Imagining as a second step was carried out based on the Double Diamond Model (DDM) (See Figure 3). Imagining was concerned with insights (what might be done with these insights?) through a codesign approach that aims to use the captured insights and or perceptions from the previous step in the entire design process by utilizing different co-design tools or methods (See Table 1). Appropriate design methodologies and instruments are then presented for every stage of the design process (See Table 1). A systematic process is undertaken based on literature; which entails mapping between the design phases and the popular co-design tools or methods as recommended by British design council (2005). The last step is building, which aims to construct a new service design using a viable prototype that will go through iterative design cycles on the basis of the tailored DDM (See Figure 5). A service co-processes design journey (or Service Blueprint) is developed to represent steps followed by diverse stakeholder groups in the process of designing the service. Service design requirements are identified for supporting the final phase where design tools and methods are adopted.

In the sections that follow, the study will describe the research method used in detail, along with target and sample population, as well as the process used to conduct the in-depth interview (i.e. plan, develop questions, collect data, analyse data, and disseminate findings) for the research paper (Boyce and Neale, 2006). In fact, these process steps are employed systematically in each step of the identified research method. 


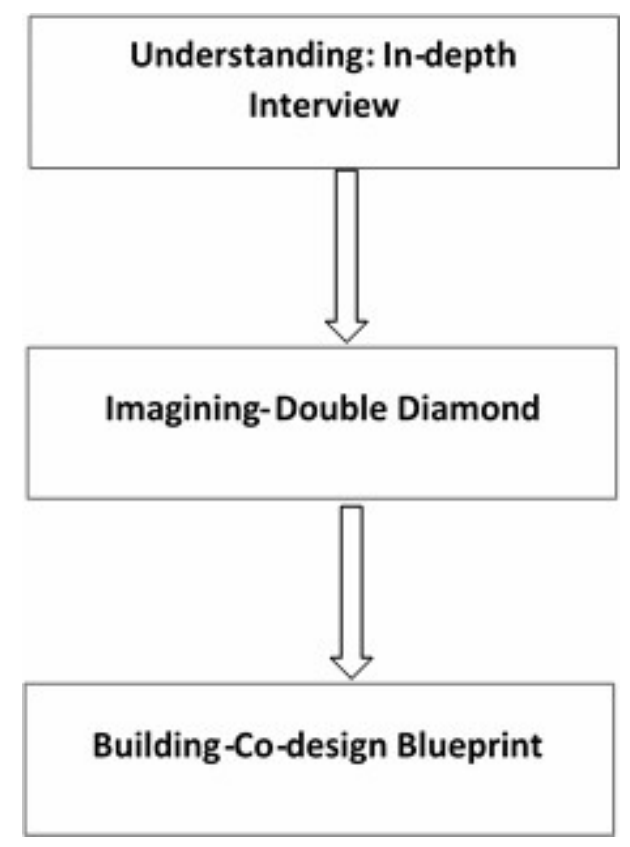

\section{Understanding: In-Depth Interview}

\section{Data Collection and Sampling}

By using in-depth interviews to gather data (Dworkin, 2012), the authors managed to categorize G2C e-service design requirements through exploring insights and views presented by research participants. Various studies (Dworkin, 2012; Boyce and Neale, 2006; MacDougall and Fudge, 2001) proved that small sample population (i.e. 5-50 respondents) is sufficient to capture a comprehensive range of requirements. This study employed purposive sampling (See Table 2) through communicating with prospective respondents different experiences. An adequate process of sampling is supposed to ensure respondents have varied experiences in order to provide detailed diverse viewpoints (Siau et al, 2010). As such, this research paper is interested in stakeholders using (i.e. users of service), dealing with (i.e. frontline staff) and/or developing (i.e. service providers) the $\mathrm{G} 2 \mathrm{C}$ e-service, because they represent the targeted population that is knowledgeable regarding needs and demands of users.

Table 2. Sample for In-depth interviews

\begin{tabular}{|l|l|l|}
\hline Stakeholders & Participants Category & \# of Participants \\
\hline Service Provider & $*$ NITB & 9 \\
\hline Service Frontline-staff & $* *$ PITB & 11 \\
\hline Service User & varied \& diverse Background \& Experience & 28 \\
\hline
\end{tabular}

*National Information Technology Board; ** Punjab Information Technology Board 
The authors chose to use interviews since they offer a chance to delve deeper into the subject being researched, compared to using surveys (Bell \& Nusir, 2017). Cumulatively, the authors carried out 48 in-depth interviews that last from 45 minutes to one hour. Nonetheless, the authors guaranteed that the experience and familiarity of all the respondents with the area of investigation (i.e. G2C e-service design process) was sufficient. All the interviews began with a brief summary of the questions in the interview (open-ended), to ensure the respondents understood the areas being investigated. Subsequently, the interviewing protocol and guidelines including additional questions were explained (See an appendix A) as an introduction as a way of facilitating the interviewing process. After a brief introduction about interview protocol, service users were supposed to answer questions about their experiences - How would you prefer (government staff) your services to be designed (Citizens')? What/how do you wish to contribute and/or enhance your experience with services and service outcomes? Service providers and frontline-staff were interviewed on prevailing processes of design - Which steps are followed by e-Government projects in Pakistan when creating government to citizen (G2C) services? The 48 respondents all resided and worked in Pakistan (See Table 2). The author interviewed service providers (i.e. government employees working in the key agencies tasked with developing government services). Among them were National Information Technology Board and Punjab Information Technology Board. Six interviews were conducted with service providers (i.e. governmental employees) in government agencies; in these interviews, staff tasked with designing and developing G2C e-services was the respondents. The second group was comprised of front-line staff working in government departments and linking service users and providers. Expectedly, front-line staffs had sufficient familiarity and experience concerning challenges associated with $\mathrm{G} 2 \mathrm{C}$ service design and unsatisfied requirements of service users since they deal with their issues and services that support interactions with citizenry. The third group was comprised of classic users of services (Citizenry as consumers) with diverse demographic characteristics (See Table 3). The stakeholder groups were comprised of nine, eleven and twenty-eight participants correspondingly. The authors captured the data through recording and transcribing the interviews. This study presents findings from the comprehensive interviews and reports them to create a better understanding of the requirements utilized for an adapted and or tailored G2C e-service design process.

\section{Data Analysis}

English translations and manual transcription of interview transcripts were exported into sheets of excel for the smooth management of the data. The inclusive thematic evaluation was used for analysis of the grouped transcripts of every participant. The authors combined all transcripts and created a single file on a data-set, which was analysed based on inductive thematic analysis. This is a popular method utilised in qualitative data analysis. This approach was chosen because of its accessibility and flexibility. Further, there were no restrictions to any specific theory, and it offered the capacity to produce the robust and changing aspects of occurrences. The description of the data-set was rich and its interpretation intense (Braun and Clarke, 2006). The thematic analysis procedure involved six key steps as proposed by Braun and Clarke (2006): 1-familiarization with data-set through reading data numerous times to attain full overall meaning overall. 2-generation of initial codes through initial analysis of the transcripts. For example, (See Table 4); the key points are considered as significant to the investigation of the transcripts of the interviews (Allan, 2003). 3-sorting the initial relevant transcripts codes to identify the potential categories. 4-review of potential themes; in this step researches take an opportunity to review and refine the potential categories in order to ensure there is consistency. 5-define and classify categories using appropriate titles. 6- Identify the satisfied categories by discussing data results in clear way that will convince reader about data analysis validity and accuracy. The research paper identified 30 requirements labels. Identification of 4 categories, including Service inauguration and scoping, delineation and organization of service, developing and deploying the service, and service launch and update. At this point, the thirty requirements labels were classified into four groups across all stakeholder groups of 48 respondents from diverse background 
Table 3. Demographic characteristics of research participants, $n *$ : Number

\begin{tabular}{|c|c|c|c|}
\hline $\begin{array}{l}\text { Demographic } \\
\text { characteristics }\end{array}$ & Service provider $* \mathbf{n}=9$ & $\begin{array}{l}\text { Service Frontline staff } \\
\mathrm{n}=11\end{array}$ & Service User $\mathbf{n}=\mathbf{2 8}$ \\
\hline \multicolumn{4}{|l|}{ Age (Year) } \\
\hline $19-24$ & 0 & 3 & 9 \\
\hline $25-34$ & 4 & 5 & 9 \\
\hline $35-44$ & 3 & 2 & 4 \\
\hline $45-55$ & 2 & 1 & 4 \\
\hline Above 55 & 0 & 0 & 2 \\
\hline \multicolumn{4}{|l|}{ Gender } \\
\hline Male & 5 & 6 & 14 \\
\hline Female & 4 & 5 & 14 \\
\hline \multicolumn{4}{|l|}{ Education Level } \\
\hline High school & 0 & 0 & 4 \\
\hline College & 3 & 2 & 6 \\
\hline $\mathrm{BSc}$ & 3 & 6 & 10 \\
\hline MSc & 2 & 3 & 4 \\
\hline $\mathrm{PhD}$ & 1 & 0 & 4 \\
\hline Other & 0 & 0 & 0 \\
\hline \multicolumn{4}{|c|}{ ICT skills \& competency } \\
\hline Very low & 0 & 0 & 5 \\
\hline Low & 0 & 0 & 7 \\
\hline Average & 1 & 6 & 8 \\
\hline High & 6 & 5 & 4 \\
\hline Very high & 2 & 0 & 2 \\
\hline I don't know ICT & 0 & 0 & 2 \\
\hline
\end{tabular}

and knowledge bases. Figure 5 depicts the necessities of requirements and categories. Categorization of results has been completed on the basis of common themes and sub-themes in subsequent subportions, for comparison between categories.

The frequency count as a criterion is required for identification of the crucial classifications left open to be interpreted within the qualitative results (Goffin et al., 2006). This criterion was implemented on the basis of the counting (i.e. frequency of mention); the requirements under each group having been mentioned by a minimum of $25 \%$ of respondents, meant they were vital in the design process of $\mathrm{G} 2 \mathrm{C}$ e-service compared to groups/requirements mentioned less frequently

\section{Imagining: Double Diamond}

Develop the building blocks of the service that you need to articulate and specify (Jisc, 2017). Designers using a range of design instruments and methodologies for planning e-services at first must outline the process (Pierri, 2012; Ruhl et al., 2014.). This study, like other studies of the same nature, started with the DDM from the UK Design Council to represent an operative way of visualizing the process of design. DDM was implemented in introducing the co-design method linked to DDM through including diverse stakeholders (i.e. employed and introduced service user, 
Table 4. In-depth interview analysis (key point coding as a manner of grounded theory) derived from the transcripts' data gathered from service users group. *KP: key-point; ${ }^{\wedge} \mathrm{SU}$ : service user

\begin{tabular}{|c|c|c|}
\hline IID & Key Point & Code \\
\hline \multirow[t]{3}{*}{ *KP-^SU-1 } & $\begin{array}{l}\text { Distribution of questionnaires by random sampling to } \\
\text { collect information on general needs of users. }\end{array}$ & User's needs \\
\hline & $\begin{array}{l}\text { Study and analysis of government potential to implement } \\
\text { requested services. }\end{array}$ & Identifying the service feasibility \\
\hline & Development the requested services. & Design and implementation \\
\hline \multirow[t]{4}{*}{ KP-SU-2 } & Opinion poll to explore needs of users. & User needs \\
\hline & $\begin{array}{l}\text { Motivate citizenry to utilise e-government services using } \\
\text { training courses and advertisements. }\end{array}$ & Citizens' willingness and awareness \\
\hline & Initiate the services. & Launch trail version- service online \\
\hline & Try a beta version of the services provided by citizens. & Testing of service \\
\hline \multirow[t]{5}{*}{ KP-SU-3 } & $\begin{array}{l}\text { Distribution of questionnaires to collect information on } \\
\text { early knowledge about needs of citizens. }\end{array}$ & Needs of citizens \\
\hline & $\begin{array}{l}\text { Seek information from stakeholders on how they wish to } \\
\text { engage in e-services process of design. }\end{array}$ & $\begin{array}{l}\text { Participation and involvement (sharing } \\
\text { and generating ideas and experience). }\end{array}$ \\
\hline & Begin the designing stage. & Design stage \\
\hline & Implementation phase & Development phase \\
\hline & Beta testing of service by back to targeted citizens. & Testing of service \\
\hline \multirow[t]{4}{*}{ KP-SU-4 } & $\begin{array}{l}\text { Build-up multiple mock-up prototypes based on the } \\
\text { requested services. }\end{array}$ & $\begin{array}{l}\text { Presentation of numerous templates of } \\
\text { service design }\end{array}$ \\
\hline & $\begin{array}{l}\text { Vote for most design templates' versions which fit with } \\
\text { citizen's experience. }\end{array}$ & choosing the best service design \\
\hline & Activation a beta service for citizens. & Launch beta- service online \\
\hline & Measure the developed services to get feedback. & Evaluation phase \\
\hline
\end{tabular}

frontline-staff, and provider of service) utilizing and/or creating the G2C e-services. It became evident that a process of design must be adapted to satisfy particular perspectives, needs, insights, and prospects of stakeholders in this G2C context. A tailored version of the DDM (See Figure 5) has been and utilized and proposed varying weights for various stages (See samples of the tailored DDM in literature sub-section). Varying weights and involvement of the stakeholders are recognized for dissimilar stages, depending on shared (intersection) interests, tasks, and requirements between participants in the groups. Accordingly, stages have been retitled to make them closely suitable to the co-design strategy (i.e. discover retitled to co-discover).

The initial two stages (co-discover and co-define) signify a crucial process of definition, while the last two stages (co-develop and deliver) signify the process of design. In Figure 5, the tailored DDM is a representation of the divergent and thought mode used in associating results from the interviews (See Figure 5). The authors classified these G2C's requirements and categorized the common requirements together as explained later in specific categories (See Figure 7). A systematic process is undertaken, that maps the identified categories across stakeholder groups (See Figure 7) and the DDM phases in relation to requirement roles (i.e. categories) and definition of each stage of design process through matching these roles and their definitions (See Table 6) (British Design Council, 2005; JiSC, 2017) to find out the most suitable and appropriate for all categories to reach the goals(s) in every stage of process of design (See Tables 1 and 6). The central diamond ('co-define and 'co-develop') along with 'co-discover' are unrelated, since they are concerted stages between engaged and participating 


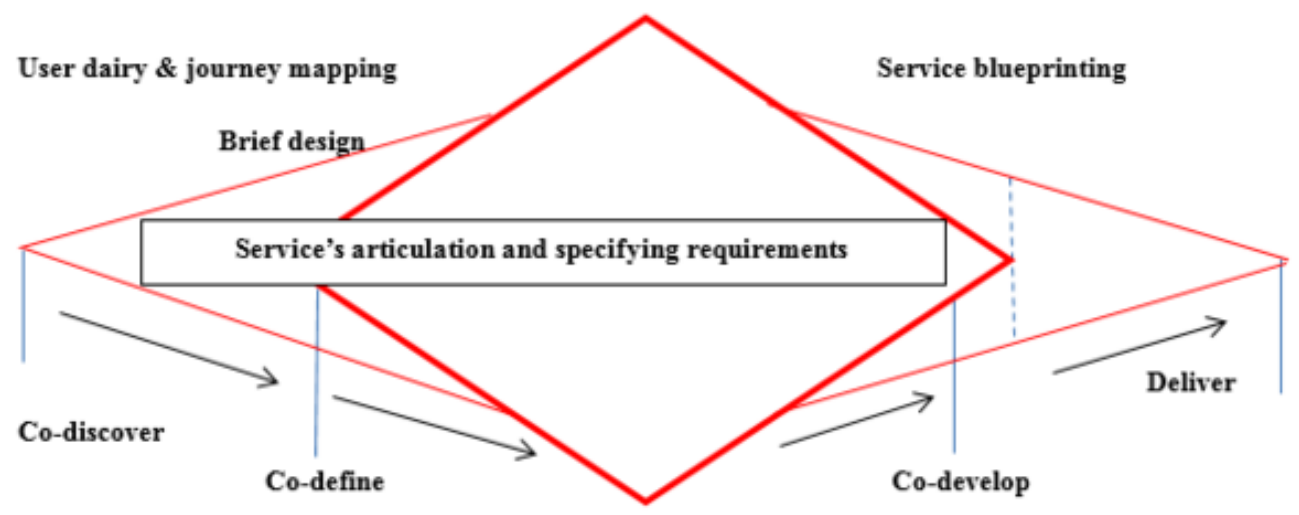

stakeholders during these stages. Further, the central diamond has an unalike magnitude because of the amount of the shared (intersection) requirements gathered and analysed from interviewees' results. Predictably, the co-define and co-develop plan processes will employ a lengthier period compared to conventional plan procedure. Additionally, it needs of time due to the co-design approach, which ought to be a 'process of learning' for involved parties (diverse stakeholders). Additional, there is overlay of dual diamonds to show initiation and beginning of the co-design. The 'broken line' at the end of the co-design stage (at the co-develop stage) shows possibility for extra collaboration of overall stakeholders combined in all the stage of the design process. In various practical instances of co-designing and specifically target services (i.e. health care services), the deliver stage is directed and lead by specialists, because of policy rules, business matters and other obstacles (British Design Council, 2007). Actually, in this research, the overlapped requirements are not evident in the delivery stage because of the non-appearance of common requirements of overall stakeholders. In contrast, in other phases, every requirement of the stakeholders was overlapped. A co-designing procedure in every stage which is matched with the stakeholders' viewpoints must then be operationalized to develop the appropriate service design blueprint.

\section{Building: Co-Design of Service Blueprinting}

In this research method stage (See Figure 4), the authors describe G2C e-service design process for users using an obvious visual overview of diverse users' journey through clearly identifying phases of the stakeholders' experiences. Business Process Modelling Notation (BPMN) - See Figure 6 - is utilised to create a practical operationalizing of the tailored DDM (See Figure 5), including appropriate design tools in various design phases. Furthermore, BPMN is constructed internally but also serves as a good way of engaging diverse stakeholders in the G2C e-service design.

The proposed design instruments and methodologies for every stage of the DDM are classified (See Table 6). Afterwards, citation analysis was used to identify this matching by positioning a high mention frequency of the produced needs adjacent to the recommended design instruments or methodology (For instance, Table 5 presents the popular instruments/methodologies in Co-discover stage). After that, we have calculated the percentage frequency of mention (derived from literature) for every design instrument/methodology by identification of the mention frequency (number of times) of the proposed design instrument/methodology, divided by the cumulative amount of mention frequencies in the design instruments for the equivalent needs as a percentile. For instance, (See Table 5) the questionnaires (as a requirement) matched with user shadowing (as a design tool), which 
reflects the highest mention frequency on the basis of citation analysis is (773) whose percentage frequency of approximately $72 \%$ (i.e. $\left.773 /(35+221+45+773))^{*} 100 \%\right)$.) The mention frequency in terms of user shadowing was divided by the cumulative amount of mentions frequencies of other design instruments for the questionnaires.

Table 5. Service inauguration and Scoping-Co-Discover Phase

\begin{tabular}{|c|c|c|c|c|}
\hline \multicolumn{5}{|c|}{ Service design tools/methods } \\
\hline Requirements & User Journey mapping & Service diary & Service safari & User shadowing \\
\hline Service user perspectives & 8 & 41 & 2 & 25 \\
\hline Questionnaires & 35 & 221 & 45 & 773 \\
\hline Citizens opinions & 4 & 22 & 4 & 13 \\
\hline End user requirements & 0 & 6 & 2 & 47 \\
\hline Service scoping & 10 & 62 & 1 & 103 \\
\hline Service studying & 21 & 417 & 9 & 201 \\
\hline User needs & 7 & 52 & 3 & 46 \\
\hline
\end{tabular}

The design instruments/methodologies were employed and used throughout service blueprinting (See Figure 6) to facilitate diverse stakeholders' involvement in G2C e-service design processes (See Table 6). According to JiSC (2017) classified the people involved in the co-design context; there are four key people roles (i.e. maker, planner, decider, and user). Authors return to the definition and key responsibilities of these people to find out which of them are well-suited fitted with diverse stakeholder groups (i.e. service provider, service frontline-staff, service user). We identified that planners represent service providers, makers represent service frontline-staff, and users represent service users. The guiding principle include three co-design stages (co-discover, co-define, and codevelop) and a consequent deliver stage.

Co-Discover: The initial phase of the co-design method is represented in this stage referred to as scoping and service initialization. A design problem(s) was recognized in this stage from the detailed analysis of in-depth interview results. Procedures, support activities and design methodologies/ instruments, which are popular in the period of interactions are beneficial to specific tasks (i.e. inputs artefact), and the design methodologies/instruments express and generate views or ideas from different participants. Therefore, they function as a processor. To help service providers or designers and provide them with a capacity to understand the needs of the service users, the contribution artefacts act as insights or observations. Therefore, in the co-define stage, these outputs will become input artefacts.

Co-Define: This stage is considered to filter ideas through collection, review, and elimination. The identified ideas from the previous stage are combined, examined and modified as a brief in assisting in the exploration of the potential solution(s) that is design-led by analysing and synthesizing the provided design ideas. The design implies that support elicited requirements is the design brief (detailed- interviews' results). This stage ends by clearly defining what the problems are, and the plan used for addressing the essential points of reference for every stakeholder involved in the codevelop stage.

Co-Develop: Here, the G2C e-service's interviewees are formerly introduced to a solution led by design (for sign-off), that has "financial and corporate (Design Council, 2007, p. 19). Resolutions for the designing process of G2C e-service (articulated concepts) are designed in this stage as an initial step. They are developed as contribution artefacts for the design methodology such as, design 


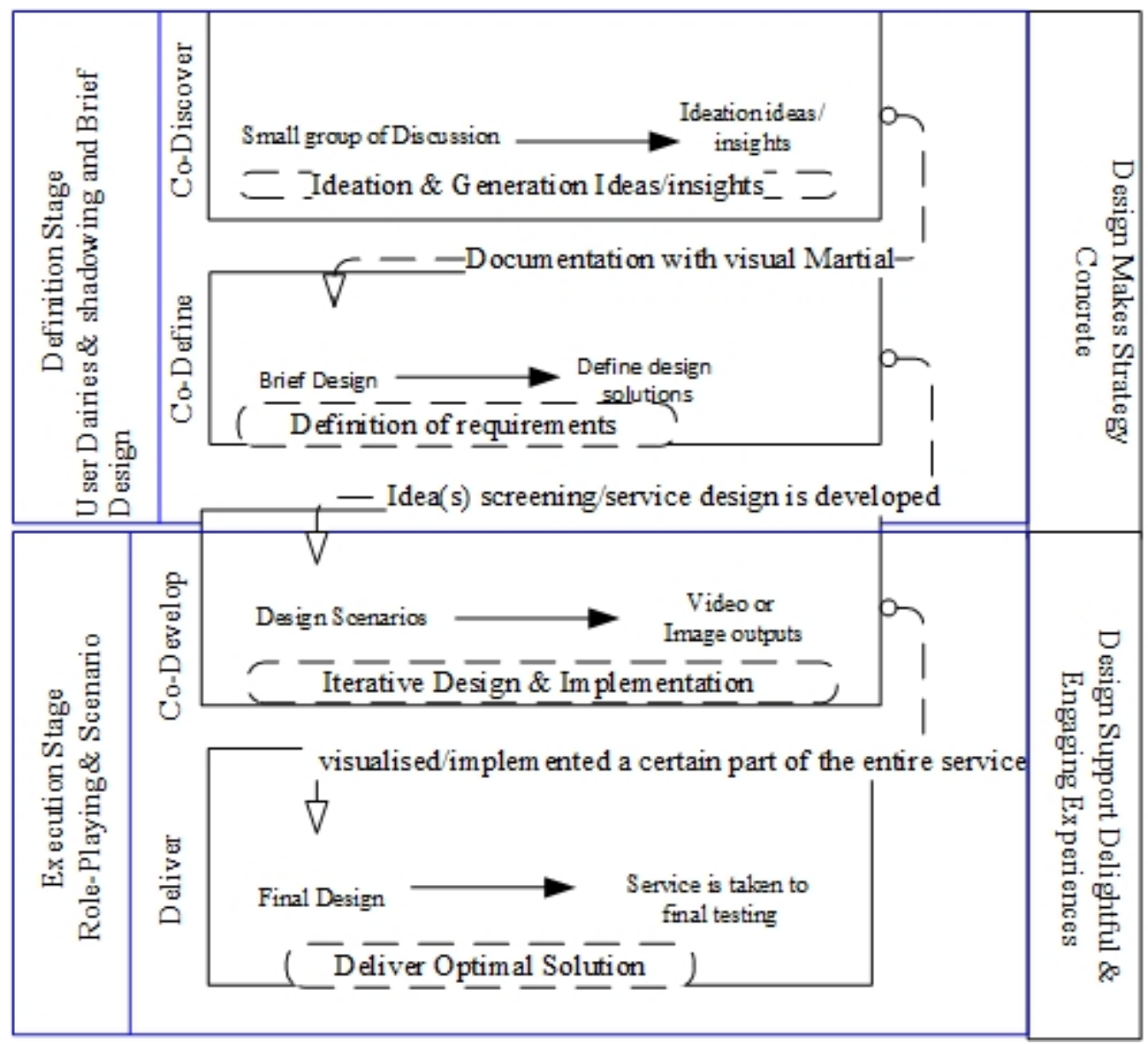

scenario and role-playing (Design Council, 2007). For implementation of service practicality with teams of design within amenity interior-provider, facilitation in communication must be done between the frontline-staff and the service users. Meanwhile, the service providers concentrate on realizing the approved services. With the processes of forming the elicited requirements into functions in the anticipated instantiation, the design scenario outputs contribute to match these requirements with processes of design. In the final phase of the co-develop stage, service development staff will have been progressed to a phase where G2C e-service is complete for launch and distribution of a beta version of provision which assists in gaining feedback that is worthwhile for keeping the service provision by improving and appraising continually.

Deliver: This stage represents the last stage for testing service and is called service assessment and updating. The artefacts that result from this stage are usable as portions of a walk-by that layer each point of contact. The delivery process involves inclusion of correlation that has the required inner design staff without involving other stakeholders (grounded on detailed interview's results), that displayed no involvement from service frontline-staff or service's users in this design stage. Nonetheless, the current research suggests that the use of stakeholder specific co-design instruments at this stage supports cooperation between design teams. 
Table 6. A co-design framework for diverse stakeholder groups involvement in $\mathrm{G} 2 \mathrm{C}$ e-service design. *Based on data results (i.e. frequency of mentions next to $\mathrm{G} 2 \mathrm{C}$ e-service design requirements under each category).

\begin{tabular}{|c|c|c|c|c|c|c|}
\hline $\begin{array}{l}\text { Service Design } \\
\text { phase }\end{array}$ & $\begin{array}{l}\text { Category across } \\
\text { all groups }\end{array}$ & $\begin{array}{l}\text { Design tool/ } \\
\text { method }\end{array}$ & $\begin{array}{l}\text { Design Tool's/ } \\
\text { Method's } \\
\text { Definition }\end{array}$ & $\begin{array}{l}\text { Key } \\
\text { responsibilities } \\
\text { during } \\
\text { Involvement } \\
\text { across all } \\
\text { groups }\end{array}$ & $\begin{array}{l}\text { Diverse } \\
\text { Stakeholders }\end{array}$ & $\begin{array}{l}\text { *Level of } \\
\text { Involvement across } \\
\text { all groups }\end{array}$ \\
\hline Co-Discover & $\begin{array}{l}\text { Service } \\
\text { inauguration and } \\
\text { scoping }\end{array}$ & $\begin{array}{l}\text { User } \\
\text { journey } \\
\text { mapping } \\
\text {-User } \\
\text { Dairy }\end{array}$ & $\begin{array}{l}\text { it's a visual } \\
\text { representation } \\
\text { that elicits } \\
\text { end-users } \\
\text { viewpoints and } \\
\text { interprets their } \\
\text { experience }\end{array}$ & $\begin{array}{l}\text { Involved } \\
\text { in actively } \\
\text { together for } \\
\text { exchanging } \\
\text { ideas/insights } \\
\text { for defining } \\
\text { clear ways to } \\
\text { learn. }\end{array}$ & $\begin{array}{l}\text { Provider, } \\
\text { frontline, } \\
\text { and user }\end{array}$ & $\begin{array}{l}\text { All groups } \\
\text { are involved. } \\
\text { However, } \\
\text { Frontline-staff is } \\
\text { highly involved. }\end{array}$ \\
\hline Co-Define & $\begin{array}{l}\text { service } \\
\text { delineation and } \\
\text { organizing }\end{array}$ & $\begin{array}{l}\text { Design } \\
\text { Brief }\end{array}$ & $\begin{array}{l}\text { A clear and easy } \\
\text { form which } \\
\text { is written and } \\
\text { synthesized } \\
\text { by stakeholder } \\
\text { together as a } \\
\text { reference point } \\
\text { for designing } \\
\text { the next phase. }\end{array}$ & $\begin{array}{l}\text { Keep } \\
\text { communicating } \\
\text { together to } \\
\text { analyse the } \\
\text { context (i.e. } \\
\text { G2C e-service } \\
\text { design) } \\
\text { development, } \\
\text { and assesses } \\
\text { the risks \& } \\
\text { potential } \\
\text { solutions }\end{array}$ & $\begin{array}{l}\text { Provider, } \\
\text { frontline, } \\
\text { and user }\end{array}$ & $\begin{array}{l}\text { All groups } \\
\text { are involved. } \\
\text { However, } \\
\text { Frontline-staff } \\
\text { and Service } \\
\text { user is highly } \\
\text { involved. }\end{array}$ \\
\hline Co-develop & $\begin{array}{l}\text { Service } \\
\text { development and } \\
\text { deployment }\end{array}$ & $\begin{array}{l}\text { Service } \\
\text { Blueprinting }\end{array}$ & $\begin{array}{l}\text { the visual } \\
\text { representation } \\
\text { which facilities } \\
\text { diverse } \\
\text { stakeholders } \\
\text { involvement } \\
\text { throughout a } \\
\text { unified structure } \\
\text { regarding } \\
\text { design } \\
\text { process by } \\
\text { understanding } \\
\text { their roles. }\end{array}$ & $\begin{array}{l}\text { Brings a lot } \\
\text { of multi- } \\
\text { disciplinary } \\
\text { diverse } \\
\text { stakeholders } \\
\text { to work } \\
\text { together to } \\
\text { improve } \\
\text { and refine } \\
\text { different } \\
\text { touch points } \\
\text { and channels, } \\
\text { as well as the } \\
\text { behind the } \\
\text { scenes parts } \\
\text { of a service. }\end{array}$ & $\begin{array}{l}\text { Provider, } \\
\text { frontline, } \\
\text { and user }\end{array}$ & $\begin{array}{l}\text { All groups } \\
\text { are involved. } \\
\text { However, a } \\
\text { service provider } \\
\text { is highly } \\
\text { involved. }\end{array}$ \\
\hline Deliver & $\begin{array}{l}\text { Service } \\
\text { launching and } \\
\text { updating }\end{array}$ & NA & NA & NA & $\begin{array}{l}\text { Service } \\
\text { provider }\end{array}$ & $\begin{array}{l}\text { Involved only by } \\
\text { a service provider }\end{array}$ \\
\hline
\end{tabular}

\section{Results and Discussion: Key Categories}

We identified the main categories based on frequency, which was the criterion's indicator. Frequency is among the crucial indicators (Goffin et al., 2006). This criterion is considered on the basis of the review of literature on mention frequency; the category mentioned by a minimum $25 \%$ as baseline of participants is considered more important (Goffin et al., 2006). A high mention frequency may be an indication that a category is clearly mentioned in a straightforward manner and very common (See Figure 7). However, the results were not $100 \%$ accurate to determine which category is highly significant. The identified categories are: 


\section{Service Development and Deployment}

Developing and deploying service is among the most significant categories next to stakeholder groups as depicted in Figure 7 (frequency of mention across stakeholder groups is 27\%). The category is exceptionally substantial in the group of service providers and temperately significant to users of the service as well as and front-line service staff. Individual stakeholders within diverse classifications view that those responsible for making decisions that affect them deliberate on the imperative necessities in this category. The needs have been distributed in order to ensure eradication of redundant requirements. The summarization of the requirements was done (See Figure 7) to facilitate comprehension: service testing, implementation by the different stakeholders (providers and users of service), formulate a draft template of a design model for demanded services, which assists to avoid any design glitches in an initial design phase. Furthermore, the initial design template directs to conserving finances, time and effort and attracting all stakeholders to be involved in the process of designing the services. That includes users of the service as persons utilizing these facilities, construct model trial product to trial and assess the created service prior to launching it to service users. The category is critical to testing the functioning of e-services, in terms of efficacy and effectiveness.

\section{Service Launching and Updating}

This group is placed last across all groups (mention frequency over all groups) with only is $15 \%$ ). That explains that the process of launching and updating must happen continuously to guarantee that the services work towards meeting the needs of the users. The requirements positioned under the group are embodied as response emanating from the service frontline personnel and service providers using service evaluation and assessment in the emerging phase of development. This category displays clearly as a significant category to service providers and it is not important by other groups (service frontline and service users). Precisely, the service provider group provided a superior insight into progress of e-services design and development based on valuable and reliable response for appraising e-service, which may occasionally be valued additionally compared to government entities steering evaluation.

\section{Service Delineation and Organizing}

Based on the responses of the stakeholder groups (mention frequency across stakeholder groups was $25 \%$ ), the study found that this category shows high significance from varied groups, although relatively low significance in service providers groups exists. Nevertheless, users of service, as well as service frontline personnel are mentioned extremely. The utmost vital requirements must be considered by decision-makers, by formulation of a novel service design progress or re-structuring of the current service design models. Authors observed an abandonment of this category from research participants, which points towards ineffectiveness of e-service growth progression. The reason is analysis of these services in regards to recognizing unmet requirements enables communication between service provider and service user. Remarkably, is a general collective consensus, the provider of service is considered to strategically manage an association with the user of the service when considering the needs, to enhance the construction stage of development.

\section{Service Inauguration and Scoping}

Unpredictably, service inauguration and scoping do not demonstrate considerable importance as a category transversely on all groups depend on (frequency of mention is $21 \%$ ). This category is substantially founded on the opinions/views of service frontline personnel. It may demonstrate that the government staff portray the greatest significant correspondence with the design glitches of the service, which occurred with users of the service because of their daily usage of these services. In contrast, this category displays the modest standing according to the providers of service and users of service based on mention frequency. Similar to the manner explained earlier, service inauguration and scoping has not been declared (i.e. frequencies). This may demonstrate that research participants 
Figure 7. Cognitive mapping for G2C e-service design requirements (across stakeholder groups) based on thematic analysis (Key point coding)

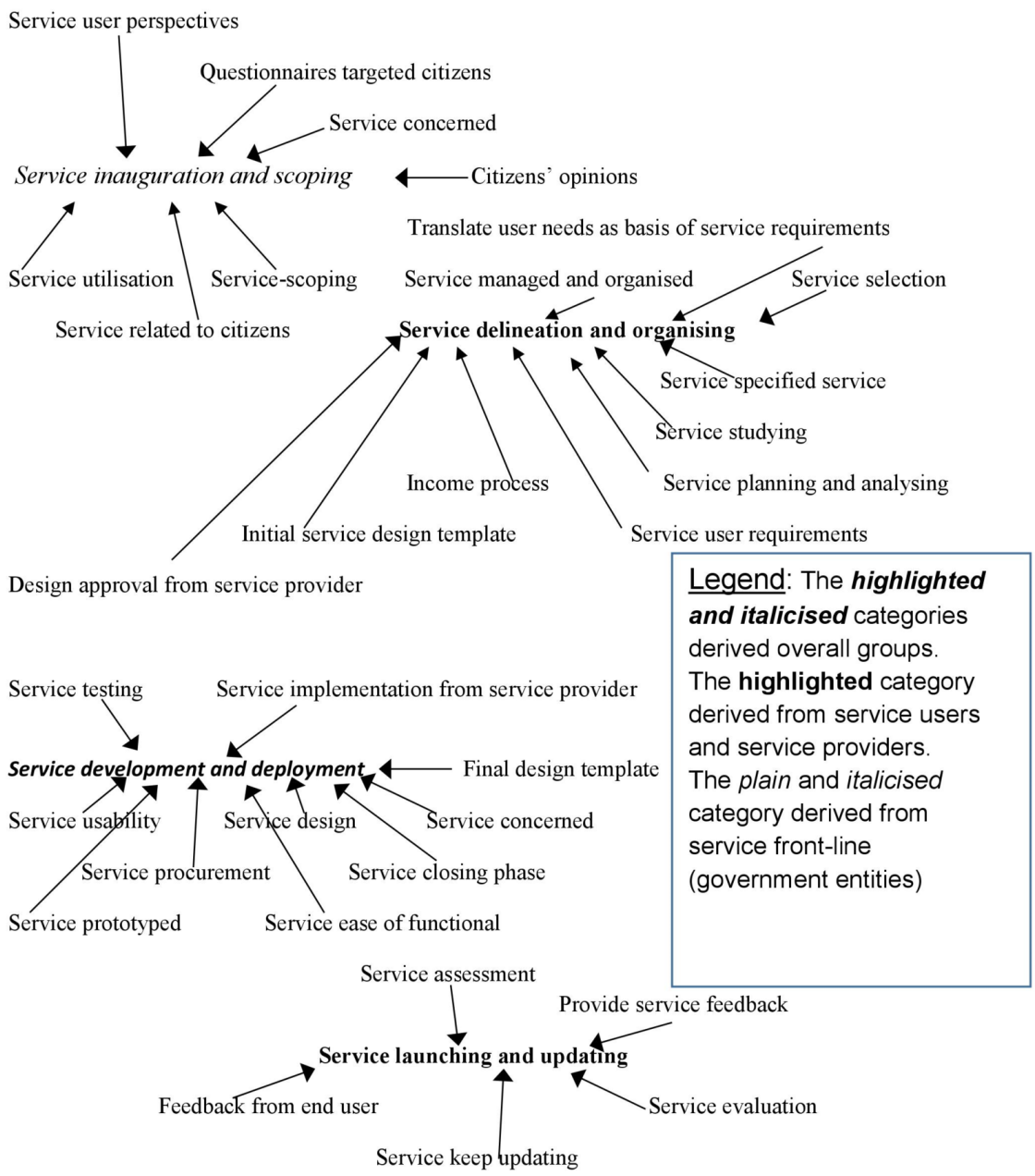

did not state this category since it was not sufficiently clear to them, and may be related to diverse insights and views. The category is contemplated as being vital for designing high-level of e-services; the requirements have been recognized concerning varied stakeholders' viewpoints using in-depth interview method. In order to connect the requirements, gap existing in regards to service user and provider (Table 7).

Table 7. Summarized of the key categories of higher importance corresponding stakeholder groups

\begin{tabular}{|l|l|l|l|}
\hline Overall groups & (service provider) & (service frontline) & (service user) \\
\hline $\begin{array}{l}\text { Developing and } \\
\text { deploying of service }\end{array}$ & $\begin{array}{l}\text { Service development and } \\
\text { deployment }\end{array}$ & $\begin{array}{l}\text { Service inauguration and } \\
\text { scoping }\end{array}$ & $\begin{array}{l}\text { Service delineation and } \\
\text { organizing }\end{array}$ \\
\hline $\begin{array}{l}\text { Service delineation and } \\
\text { organizing }\end{array}$ & ----------------- & -------------- & \\
\hline
\end{tabular}




\section{Evaluation and Discussion -Fieldwork Testing}

Thirty-two interviewees were required to give consent through signing a form that included provision of background profiles (i.e. Demographics-See Table 8). Authors were presented with a brief introduction on the proposed virtual collaborative co-design platform (See Figure 8) and its features, interviewees were granted a short duration to explain the tasks they were to assume and to assume allocated roles (i.e. roles of operation) to demonstrate that they understand the assigned task' roles (See an Appendix B). 32 semi-structured interviews (See an Appendix B) were conducted through focus group discussions (FGD) with the respondents, with high involvement, intrigue and experience associated (i.e. design G2C e-service), to attain appropriate subjective information. A prototype evaluation was conducted in Pakistan as a context with evaluation through post-test interview questions. Focus groups discussions were recorded by authors for 45 minutes to one hour. Subsequently, the respondents collaborated more with the task-based planning. Hence, they were required to answer some questions to assess their adequacy (i.e. effectiveness and convenience) as a prototype for open creation of ideas and concerted communication among various varied stakeholders.

Three main themes were inferred (Creativity and collaborative platform, Situating and tailoring co-design tools; and limitations and shortcomings of involvement) and six sub-themes (demonstrating engagement, communication, originality, design instruments of a collaborative nature, interaction and some advantages and disadvantages) were observed. These themes and sub-themes had similarities in regards to groups of service provider, users and interface groups. Nonetheless, the groups had varying viewpoints in terms of the possibilities and difficulties of utilizing a co-design methodology that includes end-users in the whole process of design. The three key themes and sub-themes were observed and classified. Each of them was explored and explained. The co-design blueprint (See Figure 6) was operationalized as a virtual collaborative co-design platform-web-based prototype (See Figure 8). The core role of this prototype was to capture and exchange point of views and ideas among stakeholder groups (with respect to the co-design Blueprint) and subsequent feedback from those groups.

Mediawiki, version 1.34.0 was used to create the proposed collaborative co-design platform since it is as a free and open source management framework for content. It is integrated using the PHP programming language with MySQL-5 database, and installed in WebMatrix 4 by Microsoft as server and run a program under the Microsoft Windows as an OS for operation purposes. The main features (See Table 9) were designed and implemented in the proposed platform (See Figure 8), which can be used to enable and facilitate usage of variety co-design tools/methods. Furthermore, the platform comprises of various extensions that have been employed for development platform's features such as plugins (for example, social media networks and forum of discussion) that can be to create flexibility to install various functions (based upon request for encouraging diverse stakeholders to participation) that require installation in the workspace. In fact, the developed platform itself was not the main contribution in the context of the study, because was designed and implemented as an individual exertion. Furthermore, it was used to test and validate our main contribution 'Co-Design Blueprinting for G2C e-service' (See Figure 6).

The main of the platform is capturing and sharing perspective (with respect to the Blueprint) and feedback that emanates from participants. The use of these tools in the facilitation of communication amongst participants was achieved through allowing participants to actively play a part in dealing with matters or contributing to a particular subject that triggers ideas. The exact design instruments/ methodology that idealized the views and ideas of participants included: 1) posting and sharing of ideas 2) asynchronous online messages. The platform, as an innovative co-design platform was developed in a collaborative platform through identification of several features (i.e. core functions as pre-defined in Table 9) as these features explain four phases of the typical design process (See fig 7). For instance, generation of checklists for potential services, creation of an account, uploading media, search boxes, a toolbox that includes options along with text boxes to facilitate provision of feedback on the process of designing services. Furthermore, evaluation and voting aspects, allowing 
Table 8. Demographic characteristics of focus groups' participants

\begin{tabular}{|c|c|c|c|}
\hline $\begin{array}{l}\text { Demographic } \\
\text { characteristics }\end{array}$ & Service provider $*_{n}=8$ & $\begin{array}{l}\text { Service Frontline staff } \\
\mathrm{n}=12\end{array}$ & Service User $n=12$ \\
\hline \multicolumn{4}{|l|}{ Age (Year) } \\
\hline $19-24$ & 0 & 2 & 4 \\
\hline $25-34$ & 1 & 4 & 3 \\
\hline $35-44$ & 4 & 4 & 3 \\
\hline $45-55$ & 3 & 1 & 1 \\
\hline Above 55 & 0 & 1 & 1 \\
\hline \multicolumn{4}{|l|}{ Gender } \\
\hline Male & 5 & 8 & 6 \\
\hline Female & 3 & 4 & 6 \\
\hline \multicolumn{4}{|l|}{ Education Level } \\
\hline High school & 0 & 0 & 1 \\
\hline College & 0 & 2 & 2 \\
\hline $\mathrm{BSc}$ & 3 & 7 & 4 \\
\hline $\mathrm{MSc}$ & 4 & 3 & 2 \\
\hline $\mathrm{PhD}$ & 1 & 0 & 2 \\
\hline Other & 0 & 0 & 1 \\
\hline \multicolumn{4}{|c|}{ ICT skills \& competency } \\
\hline Very low & 0 & 0 & 2 \\
\hline Low & 0 & 1 & 3 \\
\hline Average & 1 & 4 & 3 \\
\hline High & 5 & 6 & 2 \\
\hline Very high & 2 & 1 & 1 \\
\hline I don't know ICT & 0 & 0 & 1 \\
\hline
\end{tabular}

respondents the chance to measure the characteristics of the design of the service. Every respondent possesses an account allowing them to foster individual aspects in the recommended platform by sharing and exchanging ideas and viewpoints. Collaborative platform (See Figure 8) was constructed as an open source content management system allowing various stakeholders to develop personal ideologies, viewpoints, and attitudes by actively participating in the process of designing services. Moreover, social media instruments and platforms are employed to exchange and share the concepts of the respondents.

\section{Creativity and Collaborative Platform}

Positive reports from numerous participants regarding their experiences, were recorded when they had interacted with a proposed prototype. They even regarded the proposed prototype as being relatively fun and pleasant. Groups of Frontline-staff effectively participated in the entire process of assessment. Different participants felt the meaningfulness that emanated from collaboration with others. However, only one participant from the front-line staff raised the idea of improving the prototype's interface, (for instance, using a video lectures - in assisting various individuals who come from different 
Figure 8. Virtual Collaborative co-design platform

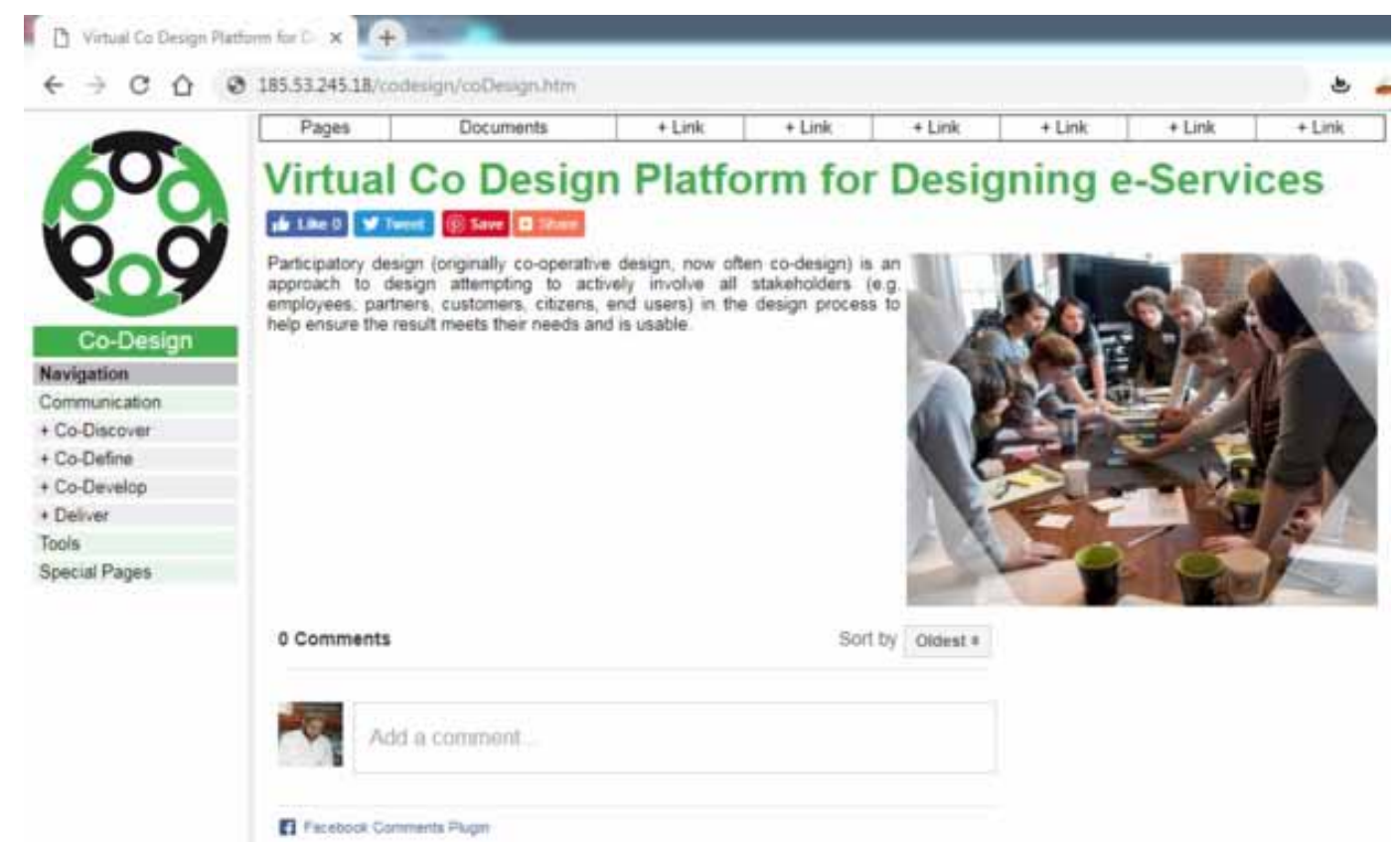

Table 9. Design features of Collaborative co-design platform (British Design Council, 2005)

\begin{tabular}{|l|l|l|}
\hline Features & $\begin{array}{l}\text { Co-Design Process's } \\
\text { Phases }\end{array}$ & Brief Definition \\
\hline User Dairy & Co-Discover & $\begin{array}{l}\text { A design method empowers } \\
\text { Participants to prompt their own ideas or perspectives in diverse } \\
\text { approaches. }\end{array}$ \\
\hline Journey Mapping & Co-Discover & $\begin{array}{l}\text { A design method synthesizes the representation which } \\
\text { elaborates the process of how an end-user interrelates with a } \\
\text { service. The process is mapped from the end-user's viewpoints. }\end{array}$ \\
\hline Brief Design & Co-Define & $\begin{array}{l}\text { A design tool can be grasped as a written template concentrates } \\
\text { on the preferred } \\
\text { features of design }\end{array}$ \\
\hline Service Blueprinting & Co-Develop & $\begin{array}{l}\text { A design tool depicts the clear interaction among varied } \\
\text { stakeholders with their service activities. }\end{array}$ \\
\hline
\end{tabular}

backgrounds on how to utilize the platform in an effective manner). Nonetheless, this theme is regarded as important, and was derived from unification of two themes (e.g. user communication and involvement, and cooperation co-design platform) because of inadequate data to support them.

The most ideal co-design methodologies/instruments (i.e. voting and rating, social media and discussions that are as a blog-based) facilitated the engagement of stakeholders over diverse phases of the service design process as shown by the responses of participants. 


\section{Situating and Tailoring Co-Design Tools}

Groups of frontline-staff participated in the assessment to contribute their outlooks on improvement or expansion of the diverse stages of the iterative design process; by maximizing the opportunity of participation and representing various stakeholders in the process of designing e-services. The previous proposal from frontline-staff groups were supported by the groups of service provider. However, their main focus was to situate co-design tools in all design stages that would assist diverse stakeholders to tailor their viewpoints. Additionally, in facilitation of the elicitation of service user' needs; utilization of the most ideal design tools in the suitable design stages can affect the e-service design process in a positive manner.

\section{Limitation and Shortcomings of Involvement}

By adopting the design instruments/methodologies in different stages of the design process, the frontline-staff groups found higher interest compared to groups of service provider. A few concerns still surround the service provider in terms of participation of users of services in the process of designing services, because of the lack of knowledge and experience; in particular, those who come from emerging nations like Pakistan (i.e. as a context case). However, groups of frontline-staff have demonstrated different opportunities through reducing these fears by supporting participants (i.e. citizenry) more meaningfully and spontaneously. The frontline-staff groups were not the same from the service providers. Hence, they concentrated on the suggestions for improvement instead of shortcomings and limitations.

\section{Implications for Future Direction}

A future direction in our research is requisite for further advancement and generalization in regard to the proposed cognitive model as co-design framework (See Figure 6) with further context that allows refinement of its main requirements so as to apply and ensure capability in addressing needs of the future. Our research study has shown that the qualitative design-orientation offers increased effectiveness, transferability, and depth, rather than full generalizability. The research study sought to lessen some context-specific bias focusing on primary practice construction of design process and selection of tools, reflecting diverse perspective of stakeholders. Additionally, the research steps have investigated the supplementary tools across disciplines with differences in stakeholders' views.

The research paper did not reflect the past experience of the participants, and therefore, the future works could inspect the experiential influences and some of the differences which might be within varied groups of participants and may affect subsequent choices of design. We acknowledged that inadequate number of features and functionalities regarding the proposed Co-design platform, which lead participants to gain a restricted perspective of the significance of collaboration and facilitation during use of the platform. Therefore, we recommend development of a beta-version similar to the proposed platform with more experiments and complex design contexts in dissimilar industrial design areas. The evaluation process for the proposed design tools that where adopted was conducted on the basis of literature without deep identification of these tools. They were tested in real-context before commissioning in the proposed prototype as a future work direction.

\section{Conclusion}

We recognized some of the significant co-design themes (e.g. Generation of ideas from users, collaborative platforms, involvement prospects and challenges, along with utilization of co-design tools) that were derived from different groups of stakeholder. The identification of the related themes and sub-themes supported the process development and design tools selection (See Figure 6). The ability to describe a design science study demonstrated co-design methodology/instrument are employed on a design process of $\mathrm{G} 2 \mathrm{C}$ e-service to create a new service. The research focused on the intermediary relation to the collaboration of providers and users of the service. Detailed interviews 
(i.e. in-depth interviews) were used to identify diverse needs of stakeholders in terms of the service design. The elements were found in the cognitive model (See Figure 6) and were then synthesized into an extension of DMM framework (See Figure 5) on the basis of British Design Council (2005). There is a need for convergent thinking in the 'co-develop' and 'co-define' stages as a way of motivating diverse stakeholders to find out the best suited strategies with a capacity to propose and plan alternate strategies through synthesis of the challenge. In comparison, the 'co-discover' stage requires more divergent thought that covers different stakeholders in a more concrete and comprehensive within the problem stage (i.e. co-discover). Operationalization of the proposed cognitive model as a codesign framework (See Figure 6) to depict certain service design stages with required design tools was used in each stage to support effective usage. Additionally, we recommended a service provider realization framework (SPRF) (See Figure 6) as guidelines for practitioners with an interest in developing e-Government services. In fact, the proposed framework as depicted in sub-section 3.3 is constructed based on tailored DDM, derived from three varied perspectives of stakeholder groups. The recommended SPRF is a co-design process for G2C e-service and contributes in two main ways: 1) Contrivance of the process of Mapping for tailored requirements of $\mathrm{G} 2 \mathrm{C}$ e-Service in the fit Design process stages 2) Selection Process mechanism to match the e-Service design categories (i.e. elements of design) with appropriate design instruments and methodologies in every stage of the process of design. With this, operationalized process of design, an applicable and flexible approach is presented, which can facilitate communication and interaction among stakeholders throughout the design process for $\mathrm{G} 2 \mathrm{C}$ e-service.

The paper identified a design science analysis that utilizes meta-design to create a particular e-Government service co-design framework for the participants. A series of researches have shown that e-Government service providers usually build e-Government services and often ignore endusers. Shockingly, the service customer is frequently omitted from the planning process, which reduces the possibility of satisfying his desires and aspirations. Its focused on integration between residents and government with many e-Government partners. Interviewed people, utility suppliers and intermediaries, the RepGrid approach was used to revealing their cognitive structures and experiences in this sense of government service architecture. The cognitive perspective then summed up components into a wider co-design paradigm which is founded on the double diamond system of the United Kingdom Design Council. The system was then operationally defined (as a BPMN model) for particular processes of program creation and support tools to promote the co-design of e-Government Systems.

The structure expands the framework for two diamonds by offering an improved description of convergent and divergent 'pension modes,' as seen in RepGrid findings. The 'co-defining' and 'co-developing' phases involve convergent thinking in order to encourage multiple players to create realistic planning plans and propose alternative approaches by summarizing the issue. Co-discovery needs more divergent thinking that includes different parties to investigate more deeply and to analyze the issue. The operationalized implementation framework offers an effective approach to the development of digital technologies within the framework of the government. Interestingly, the speech and ranking tools among the participants were especially common.

\section{ACKNOWLEDGMENT}

The authors would like to acknowledge of the appreciation of the Prince Sattam bin Abdulaziz University. 


\section{REFERENCES}

Alam, I. (2002). An exploratory investigation of user involvement in new service development. Journal of the Academy of Marketing Science, 30(3), 250-261. doi:10.1177/0092070302303006

Ali, M. A., Hoque, M. R., \& Alam, K. (2018). An empirical investigation of the relationship between e-government development and the digital economy: The case of Asian countries. Journal of Knowledge Management, 22(5), 1176-1200. doi:10.1108/JKM-10-2017-0477

Allan, G. (2003). A critique of using grounded theory as a research method. Electronic Journal of Business Research Methods, 2, 1-10.

Almakki, R. (2009). Communities of Practice and Knowledge Sharing in E-government Initiatives. The University of Manchester.

Anthopoulos, L. G., Siozos, P., \& Tsoukalas, I. A. (2007). Applying participatory design and collaboration in digital public services for discovering and re-designing e-Government services. Government Information Quarterly, 24(2), 353-376. doi:10.1016/j.giq.2006.07.018

Ardito, C., Buono, P., Costabile, M. F., Lanzilotti, R., \& Piccinno, A. (2012). End users as co-designers of their own tools and products. Journal of Visual Languages and Computing, 23(2), 78-90. doi:10.1016/j.jvlc.2011.11.005

Axelsson, K., \& Melin, U. (2007, September). Talking to, not about, citizens-Experiences of focus groups in public e-service development. In International Conference on Electronic Government (pp. 179-190). Springer. doi:10.1007/978-3-540-74444-3_16

Bell, D., \& Nusir, M. (2017, January). Co-design for government service stakeholders. Proceedings of the 50th Hawaii International Conference on System Sciences. doi:10.24251/HICSS.2017.307

Binder, T., Brandt, E., \& Gregory, J. (2008). Design participation. Academic Press.

Boyce, C., \& Neale, P. (2006). Conducting in-depth interviews: A guide for designing and conducting in-depth interviews for evaluation input. Academic Press.

Braun, V., \& Clarke, V. (2006). Using thematic analysis in psychology. Qualitative Research in Psychology, 3(2), 77-101. doi:10.1191/1478088706qp063oa

Bridge, C. (2012). Citizen Centric Service in the Australian Department of Human Services: The Department's Experience in Engaging the Community in Co-design of Government Service Delivery and Developments in E-Government Services [澳大利亚人类服务部以公民为中心的服务: 该部门在促进群体参与协同设 计政府服务提供和发展在电子政府的经验]. Australian Journal of Public Administration, 71(2), 167-177. doi:10.1111/j.1467-8500.2012.00763.x

British Design Council. (2005). The double diamond design process model. Available at https://www. designcouncil.org.uk/designprocess/

Butt, N., Warraich, N. F., \& Tahira, M. (2019). Development level of electronic government services: An empirical study of e-government websites in Pakistan. Global Knowledge, Memory and Communication, 68(1/2), 33-46.

Chandio, A. R., Haider, Z., Ahmed, S., Ali, M., \& Ameen, I. (2018). E-government in Pakistan: Framework of opportunities and challenges. GSJ, 6(12).

Choudrie, J., Wisal, J., \& Ghinea, G. (2009). Evaluating the usability of developing countries'e-government sites: a user perspective. Electronic Government, an International Journal, 6(3), 265-281.

Clune, S. J., \& Lockrey, S. (2014). Developing environmental sustainability strategies, the Double Diamond method of LCA and design thinking: A case study from aged care. Journal of Cleaner Production, 85, 67-82. doi:10.1016/j.jclepro.2014.02.003

Denzin, N., \& Lincoln, Y. (Eds.). (2000). Handbook of Qualitative Research. Sage Publication Inc.

Design Council. (2007). The design process: Eleven lessons: managing design in eleven global companies. Available at: https://webarchive.nationalarchives.gov.uk/20080821115409/ designcouncil.org.uk/en/about-design/ managingdesign/the-study-of-the-design-process 
Dworkin, S. L. (2012). Sample size policy for qualitative studies using in-depth interviews. In Electronic Government (pp. 1-9). Springer.

Fischer, G., \& Giaccardi, E. (2006). Meta-design: A framework for the future of end-user development. In End user development (pp. 427-457). Springer. doi:10.1007/1-4020-5386-X_19

Fogli, D., \& Provenza, L. P. (2012). A meta-design approach to the development of e-government services. Journal of Visual Languages and Computing, 23(2), 47-62. doi:10.1016/j.jvlc.2011.11.003

Følstad, A., Jørgenssen, H. D. \& Krogstie, J. (2004). User involvement in e-Government development projects. Proceedings of the third Nordic. Conference on Human-computer interaction, 217-224.

Friedrich, P. (2013). Web-based co-design: Social media tools to enhance user-centred design and innovation processes. Academic Press.

Glushko, R. J., \& Tabas, L. (2009). Designing service systems by bridging the "front stage" and "back stage". Information Systems and e-Business Management, 7(4), 407-427. doi:10.1007/s10257-008-0106-0

Goffin, K., Lemke, F., \& Szwejczewski, M. (2006). An exploratory study of 'close'supplier-manufacturer relationships. Journal of Operations Management, 24(2), 189-209. doi:10.1016/j.jom.2005.05.003

Graening, L., \& Sendhoff, B. (2014). Shape mining: A holistic data mining approach for engineering design. Advanced Engineering Informatics, 28(2), 166-185. doi:10.1016/j.aei.2014.03.002

Heeks, R. (2003). Most egovernment-for-development projects fail: how can risks be reduced? (Vol. 14). Institute for Development Policy and Management, University of Manchester.

Hinman, R. (2012). The mobile frontier. O'Reilly Media, Inc.

Holgersson, J., \& Karlsson, F. (2014). Public e-service development: Understanding citizens' conditions for participation. Government Information Quarterly, 31(3), 396-410. doi:10.1016/j.giq.2014.02.006

JISC. (2017). The co-design playbook: Strategies for collaborative innovation. Available at http://repository. jisc.ac.uk/6658/1/co-design-playbook-2017.pdf/

JustInMind. (2018). The Double Diamond model: what is it and should you use it? Available at https://www. justinmind.com/blog/double-diamond-model-what-is-should-you-use/

Karlsson, F., Holgersson, J., Söderström, E., \& Hedström, K. (2012). Exploring user participation approaches in public e-service development. Government Information Quarterly, 29(2), 158-168. doi:10.1016/j.giq.2011.07.009

Kaschek, R., Matthews, C., Schewe, K. D., \& Wallace, C. (2006). Information systems design: Through adaptivity to ubiquity. Information Systems and e-Business Management, 4(2), 137-158. doi:10.1007/s10257-005-0028-Z

Koh, C. E., Ryan, S., \& Prybutok, V. R. (2005). Creating Value through Managing Knowledge in an E-Government to Constituency (G2C) Environment. Journal of Computer Information Systems, 45(4), 32-41. doi:10.1080/0 8874417.2005.11645853

Kumar, R. (2019). Research methodology: A step-by-step guide for beginners. Sage Publications Limited.

Lenk, K., \& Traunmüller, R. (2002). Electronic government: where are we heading? Academic Press.

MacDougall, C., \& Fudge, E. (2001). Planning and recruiting the sample for focus groups and in-depth interviews. Qualitative Health Research, 11(1), 117-126. doi:10.1177/104973201129118975 PMID:11147158

Mager, B. (2008). Service design. In Design dictionary (pp. 354-357). Birkhäuser Basel. doi:10.1007/978-37643-8140-0_244

Magnusson, P. R. (2009). Exploring the Contributions of Involving Ordinary Users in Ideation of Technology-Based Services*. Journal of Product Innovation Management, 26(5), 578-593. doi:10.1111/j.1540-5885.2009.00684.x

Magnusson, P. R., Matthing, J., \& Kristensson, P. (2003). Managing user involvement in service innovation: Experiments with innovating end users. Journal of Service Research, 6(2), 111-124. doi: $10.1177 / 1094670503257028$ 
Merholz. (2013). The Double Diamond Model of Product Definition and Design. Retrieved from https://www. peterme.com/2013/09/26/the-double-diamond-model-of-product-definition-and-design/

OECD. (2003). The Case for e-government: Excerpts from the OECD Report "the e-government Imperative. OECD Journal on Budgeting, 3(1), 61-96. doi:10.1787/budget-v3-art5-en

Olphert, W., \& Damodaran, L. (2007). Citizen participation and engagement in the design of e-government services: The missing link in effective ICT design and delivery. Journal of the Association for Information Systems, 8(9), 27. doi:10.17705/1jais.00137

Ovais Ahmad, M., Markkula, J., \& Oivo, M. (2013). Factors affecting e-government adoption in Pakistan: a citizen's perspective. Transforming Government: People, Process and Policy, 7(2), 225-239.

Palvia, S. C. J., \& Sharma, S. S. (2007, December). E-government and e-governance: definitions/domain framework and status around the world. In International Conference on E-governance (pp. 1-12). Academic Press.

Parent, M., Vandebeek, C. A., \& Gemino, A. C. (2005). Building citizen trust through e-government. Government Information Quarterly, 22(4), 720-736. doi:10.1016/j.giq.2005.10.001

Pierri. (2012). Co-designing the healthcare: the importance of the design process. MedLove human centered healthcare experience design: UX and healthcare summit. Retrieved from http://medlove2012.blogspot. de/2012/11/co-designinghealthcare-importance-of.html

Qaiser, N., \& Khan, H. G. A. (2010). E-government challenges in public sector. International Journal of Computational Science, 7(5), 310-317.

Rehman, M., Esichaikul, V., \& Kamal, M. (2012). Factors influencing e-government adoption in Pakistan. Transforming Government: People, Process and Policy, 6(3), 258-282. doi:10.1108/17506161211251263

Rodger, J., Murrar, A., Chaudhary, P., Foley, B., Balmakhtar, M., \& Piper, J. (2020). Assessing American Presidential Candidates Using Principles of Ontological Engineering, Word Sense Disambiguation, and Data Envelope Analysis. Management, 20, 22.

Ruhl, E., Richter, C., Lembke, J., \& Allert, H. (2014). Beyond methods: Co-creation from a practice-oriented perspective. In Proceedings of Design Research Society Biennial International Conference, Umeå, Sweden (Vol. 1, No. 1, pp. 967-979). Academic Press.

Sanders, E. B.-N., \& Stappers, P. J. (2008). Co-creation and the new landscapes of design. CoDesign, 4(1), 5-18. doi:10.1080/15710880701875068

Sanders, E. B.-N., \& Westerlund, B. (2011). Experiencing, exploring and experimenting in and with co-design spaces. Nordes.

Sanders, L. (2008). On Modeling: An evolving map of design practice and design research. Interactions, 15, 13-17.

Scholl, H. J. (2014). The EGOV research community: An update on where we stand. In Electronic Government (pp. 1-16). Springer.

Scott and Fyfe. (2013). Innovation. Available from: http://www.scott-fyfe.com/innovation.aspx

Siau, K., Tan, X., \& Sheng, H. (2010). Important characteristics of software development team members: An empirical investigation using Repertory Grid. Information Systems Journal, 20(6), 563-580. doi:10.1111/j.13652575.2007.00254.x

Stappers, P. J., Vanrijn, H., Kistemaker, S., Hennink, A., \& Sleeswijk Visser, F. (2009). Designing for other people's strengths and motivations: Three cases using context, visions, and experiential prototypes. Advanced Engineering Informatics, 23(2), 174-183. doi:10.1016/j.aei.2008.10.008

Steen, M., Manschot, M., \& De Koning, N. (2011). Benefits of co-design in service design projects. International Journal of Design, 5(2).

Stegaru, G., Danila, C., Sacala, I. S., Moisescu, M., \& Stanescu, A. M. (2015). E-Services quality assessment framework for collaborative networks. Enterprise Information Systems, 9(5-6), 583-606.

Twizeyimana, J. D., \& Andersson, A. (2019). The public value of E-Government-A literature review. Government Information Quarterly, 36(2), 167-178. doi:10.1016/j.giq.2019.01.001 
UN. (2012). E-government Survey, E-government for People. United Nation.

User Centred Design. (2012). Better Services by Design (BSBD). Available at http://www.bsbd.org.uk/doublediamond-design-process/

van Velsen, L., van der Geest, T., ter Hedde, M., \& Derks, W. (2009). Requirements engineering for e-Government services: A citizen-centric approach and case study. Government Information Quarterly, 26(3), 477-486. doi:10.1016/j.giq.2009.02.007

Visser, F. S., Stappers, P. J., Van der Lugt, R., \& Sanders, E. B. (2005). Context mapping: Experiences from practice. CoDesign, 1(2), 119-149. doi:10.1080/15710880500135987

Warriach, N.F. \& Tahira, M. (2015). Impact of information and communication technologies on research and development: a case of university of the Punjab-Pakistan. Pakistan Journal of Library and Information Management, 15.

Wever, R., Van Kuijk, J., \& Boks, C. (2008). User-centred design for sustainable behaviour. International Journal of Sustainable Engineering, 1(1), 9-20. doi:10.1080/19397030802166205

Wu, A., Convertino, G., Ganoe, C., Carroll, J. M., \& Zhang, X. L. (2013). Supporting collaborative sense-making in emergency management through geo-visualization. International Journal of Human-Computer Studies, 71(1), 4-23. doi:10.1016/j.ijhcs.2012.07.007

Zhao, Y., Tang, L. C., Darlington, M. J., Austin, S. A., \& Culley, S. J. (2008). High value information in engineering organisations. International Journal of Information Management, 28(4), 246-258. doi:10.1016/j. ijinfomgt.2007.09.007

Muneer Nusir is a PhD holder in the field of Information Systems \& Computing. I awarded my PhD degree from Brunel university-London July 2015, and my research interest is on Digital Service Co-design, Human Centred design. The bachelor degree was completed on 2006 in Computer Information Systems from the Department of CIS, Jordan University of Science and Technology, Jordan. My master degree was in IT/MANAGEMENT track from Collage of Art \& Science, Applied Science. University of UTARA, Malaysia. 2008 I attended a number of training courses and published several research Papers (Conferences \& refereed Journals). My research interest falls within Digital Service Co-design, Human centered Design, and business process variability management. I have teaching, practical and research experience. My experience in teaching incorporates: Jan 2016-present, Assistant prof in Information Systems Dept, college of computer engineering \& Sciences, prince Sattam bin Abdulaziz university (PSAU)-KSA, Since August 2019-August 2021 a chairman of IS department; September 2015-JAN 2016: Visitor Lecturer, the Department of computer information System at Jordan University of Science \& Technology. 2011 (1 year) I was Teaching Assistant, the Department of Computer Science, Leicester University-UK. 2009 to 2010: Lecturer, Al-Huson University College is one of the AL-Balqa University educational institutions in Faculty of Science and Information Technology, Jordan. 2009 to 2010; Lecturer (part-time) in Jerash private University in department of computer science since, Jordan. I am the corresponding author: moneer.techno@gmail.com.

Usman Tariq is a skilled research engineer with a doctorate in Information and Communication Technology in Computer Science from Ajou University, S. Korea. Strong background in ad hoc networks and network communications. Experienced in managing and developing projects from conception to completion. Have worked in large international scale and long-term projects with multinational organizations. Currently, he is attached with Prince Sattam bin Abdulaziz University as an associate professor in College of Computer Engineering and Sciences. Usman's research interests span networking and security fields. His current research is focused on several network security problems: botnets, denial-of-service attacks, and IP spoofing. Additionally, he is interested in $l o T$ and methodologies for conducting security.

Tariq Ahamed Ahanger is currently an Associate Professor with the Department of Information Systems, College of Computer Engineering and Sciences, Prince Sattam Bin Abdulaziz University. He has authored over 40 referred papers. 